\title{
Looking through systemic credit risk: determinants, stress testing and market value
}

Instituto

Complutense de Análisis Económico

\author{
Alvaro Chamizo \\ BBVA
}

Alfonso Novales

Instituto Complutense de Análisis Económico (ICAE), and

Department of Economic Analysis, Facultad de Ciencias Económicas y Empresariales, Universidad Complutense, Madrid, Spain

\begin{abstract}
We provide a methodology to estimate a Global Credit Risk Factor (GCRF) from CDS spreads using the information provided by the default-related component of observed spreads. These are previ- ously estimated using Pan and Singleton (2008) methodology. The estimated factor contains higher explanatory power on CDS spread fluctuations across sectors than standard credit indices like iTraxx or CDX. We find a positive association between GCRF and implied volatility variables, and a negative association with MSCI stock market sector indices as well as with interest rates and with the slope and the curvature of the term structure. Such correlations provide useful insights for risk management as well as for the hedging of credit portfolios. Indeed, we present a synthetic factor regression model for GCRF that we apply in a stress testing methodology for credit portfolios as well as to evaluate future credit risk scenarios. Finally, we show evidence suggesting that the exposure to systemic credit risk was priced in the market during the 2006-2015 period.
\end{abstract}

Keywords Credit Risk, Systemic Risk, Idiosyncratic Risk, Stress Tests, Factor Models, Market Pricing

JEL classification: E44, F34, G01, G11, G23, G32

\section{Working Paper no 1927}

September, 2019

UNIVERSIDAD

COMPLUTENSE

MADRID

ISSN: 2341-2356

WEB DE LA COL ECCIÓN: http://www.ucm.es/fundamentos-analisis-economico2/documentos-de-trabajo-del-icaeWorking papers are in draft form and are distributed for discussion. It may not be reproduced without permission of the author/s. 


\title{
Looking through systemic credit risk: determinants, stress testing and market value
}

\author{
Authors: \\ Álvaro Chamizo ${ }^{1},{ }^{2}$ \\ Alfonso Novales ${ }^{34}$
}

\begin{abstract}
We provide a methodology to estimate a Global Credit Risk Factor (GCRF) from CDS spreads using the information provided by the default-related component of observed spreads. These are previously estimated using Pan and Singleton (2008) methodology. The estimated factor contains higher explanatory power on CDS spread fluctuations across sectors than standard credit indices like iTraxx or CDX. We find a positive association between GCRF and implied volatility variables, and a negative association with MSCI stock market sector indices as well as with interest rates and with the slope and the curvature of the term structure. Such correlations provide useful insights for risk management as well as for the hedging of credit portfolios. Indeed, we present a synthetic factor regression model for GCRF that we apply in a stress testing methodology for credit portfolios as well as to evaluate future credit risk scenarios. Finally, we show evidence suggesting that the exposure to systemic credit risk was priced in the market during the 2006-2015 period.
\end{abstract}

JEL classification: E44, F34, G01, G11, G23, G32

Keywords: Credit Risk, Systemic Risk, Idiosyncratic Risk, Stress Tests, Factor Models, Market Pricing

\footnotetext{
${ }^{1}$ Álvaro Chamizo: BBVA. e-mail: alvaro.chamizo@bbva.com.

${ }^{2}$ This article reflects the opinions of the author, but not the opinion of BBVA.

${ }^{3}$ Alfonso Novales, Instituto Complutense de Análisis Económico (ICAE) and Departamento de Análisis Económico, Facultad de Ciencias Económicas y Empresariales, Campus de Somosaguas, Universidad Complutense (28223 Madrid). Financial support by grants ECO2015-67305-P, PrometeoII/2013/015, Programa de Ayudas a la Investigación from Banco de España is gratefully acknowledged.

${ }^{4}$ We thank Pedro Serrano for comments and suggestions on a previous version of the paper.
} 


\title{
Looking through systemic credit risk: determinants, stress testing and market value
}

\begin{abstract}
We provide a methodology to estimate a Global Credit Risk Factor (GCRF) from CDS spreads using the information provided by the default-related component of observed spreads. These are previously estimated using Pan and Singleton (2008) methodology. The estimated factor contains higher explanatory power on CDS spread fluctuations across sectors than standard credit indices like iTraxx or CDX. We find a positive association between GCRF and implied volatility variables, and a negative association with MSCI stock market sector indices as well as with interest rates and with the slope and the curvature of the term structure. Such correlations provide useful insights for risk management as well as for the hedging of credit portfolios. Indeed, we present a synthetic factor regression model for GCRF that we apply in a stress testing methodology for credit portfolios as well as to evaluate future credit risk scenarios. Finally, we show evidence suggesting that the exposure to systemic credit risk was priced in the market during the 2006-2015 period.
\end{abstract}

JEL classification: E44, F34, G01, G11, G23, G32

Keywords: Credit Risk, Systemic Risk, Idiosyncratic Risk, Stress Tests, Factor Models, Market Pricing

\section{Introduction}

From the point of view of credit risk, financial regulators focused before the financial crisis on the amount of capital to be required to each firm individually according to the probability of default of their debtors, as specified in BIS II. But the 2007 episode showed that the stand-alone risk of each company was not the only characteristic that should be considered. Rather, the contribution of a given firm to the risk of the whole portfolio or the possible contagion to the rest of firms should also be considered when determining capital requirements. It became clear that to establish the appropriate framework for the prevention of financial crisis it is crucial for financial supervisors to fully understand how systemic is a firm and how contagion propagates to the firms across the economy (see Ballester et al. (2016)). By summarizing the information provided by credit derivatives across sectors and regions, a global credit risk factor (GCRF) can be a useful tool to evaluate the extent to which the credit risk from a given firm has a systemic nature.

Another area of interest for a global credit risk factor comes from hedging CVA risk. The market risk framework of Basel II BCBS (2006) required banks to have enough capital to face the potential decline in net present value of their portfolio of derivatives, without any requirement on credit value 
adjustment (CVA). Later on, Basel III BCBS (2011) addressed this weakness by introducing the CVA variability charge. Unfortunately, the CVA hedge currently recognized by regulators is based on an individual CDS issuer for a single counterparty, which is often illiquid and subject to wrong-way risk or, under certain circumstances, a CDS index. The good news is that, by focusing on the hedging of liquid market risk components, a CVA desk could reduce its mark-to-market volatility even if it is not hedged against its idiosyncratic risk of default on illiquid names. In fact, this consideration might lead future Basel capital requirements to spur more liquid hedges (for example, equity hedges) that are currently quite demanding in terms of regulatory capital. A global credit risk factor might help to proxy market CVA, with the sensitivity of a credit portfolio to the global risk factor and the relevance of the different factors underlying the latter indicating the type of partial hedge needed for the portfolio. The sensitivity of credit risk from a particular sector or a geographic region to the global credit risk factor should help to take positions in anticipation of events affecting global risk and, in particular, to design an efficient hedge of a credit portfolio. Furthermore, characterizing whether the more important sources of fluctuations in the global credit risk factor are macroeconomic, financial, or of some other type would also help to evaluate the relevance of the different sources of risk for any credit portfolio.

The goal of this paper is precisely to present a simple methodology to characterize a global credit risk factor, characterize its main determinants, examine its potential role for stress-testing analysis, and discuss whether systemic risk is valued in the market. A global credit risk factor should be considered as a key indicator for adequate risk management in a financial institution for several reasons: $i$ ) it would help to detect extreme credit scenarios, $i$ ) it could anticipate an intensive default cycle, given its expected correlation with the global growth cycle, and iii) it would also be pertinent for the dynamic management of CVA. In essence, a global credit risk factor is an appropriate tool for evaluating the systemic and the idiosyncratic components of risk in any credit portfolio.

The most widely used measures of systemic risk are based on information on CDS spreads, which are forward-looking and reflect the market perception of the credit risk of a particular issuer. We first construct sectorial credit indices from CDS spread data by pooling together CDS data from individual firms in a given sector from different regions. After that, we use the Pan and Singleton (2008) methodology to extract the default-related component of spreads in these sectorial indices, and we perform a principal component analysis across them to construct a global credit risk factor, which is designed to capture as much relevant information from the credit markets as possible. The observed high commonality among sectorial indices suggests that our proposed characterization of a global credit risk factor is a reasonable choice. Furthermore, our estimated global credit risk factor is correlated with existing risk indicators not based in the credit market. We use a variety of indicators to explore the potential influences on the proposed global credit risk factor, and illustrate its use for stress testing exercises. We end up by analyzing whether systemic credit risk is valued in the market.

We work with data at the level of industry sectors according to the Industry Classification Bench- 
mark, since we want to characterize the degree of commonality among sectors as well as to determine the main drivers of systemic credit risk. Our proposal is an empirical framework that can be used by financial institutions to manage their risk, and it can provide crucial information for financial markets supervisors and regulators. It would be clearly interesting to examine similar questions at the level of firms, but we feel that it is necessary first to understand well the interrelations and characteristics of sectorial credit portfolios, which are seldom considered in empirical work. However, the application of our methodology to any credit portfolio is straightforward.

We build a four-factor model of the global credit risk factor that summarizes its main determinants: stock market indices, the slope of the term structure, the level of medium- and long-term rates, and measures of implied volatility from credit derivatives. Besides, the factor model can be readily extended to any credit portfolio using its beta with respect to the global credit risk factor. The 2006-2015 sample offers the possibility of analyzing how the answer to all these issues changes under different market situations. In particular, we examine whether fluctuations in the global credit risk factor can be better interpreted as being due to interest rate shocks, stock market shocks, shocks in risk aversion or in macroeconomic indicators, and how these effects have changed their relevance over time. We do this by using both recursive estimation and quantile regression techniques. If such changes are significant, constant parameter models would be clearly inappropriate for risk evaluation and management.

Finally, we provide some evidence on the market price of the estimated global credit risk factor. Iannotta and Pennacchi (2012) suggested that banks' moral hazard incentive to increase systematic risk is based on the fact that loan and bond credit spreads reflect risk-neutral expected default losses while regulators set capital requirements and/or deposit insurance premia based on credit ratings that reflect physical expected default losses. Such regulation-induced moral hazard would be particularly devastating to banking system stability because banks would herd into the most systematically risky investments, making simultaneous bank failures particularly sensitive to economic downturns. This might be a threat to financial institutions, or even to the whole financial system. We analyze whether this type of global credit risk is valued in the market following two different strategies: First, comparing the time behavior of spreads in CDS portfolios constructed on the basis of the global credit risk factor betas of individual firms. Secondly, by running a Fama-Macbeth type of estimation exercise of CDS portfolio spreads. As expected, we obtain statistically significant estimates of the price of credit market beta-risk, but also for the price of global credit risk factor beta-risk. By providing empirical evidence for the pricing of systemic risk on CDS markets, our research contributes to alleviating the concern over the market valuation of systemic risk.

Our analysis can be very relevant to develop a forward-looking methodology of financial provisions for expected losses as requested by the new International Financial Reporting Standard (IFRS 9) published by IASB (2014). Since the historical default rates implied by credit ratings assigned by agencies such as Standard \& Poor's or Moody's are historical rates for corporate debt, they would not satisfy 
the IFRS 9 standards that require the calculation of expected losses based on current conditions and forecasts of future conditions, specified on the basis of reasonable and supportable information.

The sensitivity of a given credit portfolio to the risk factors can be updated from time to time and stored, allowing for the simulation of the response of credit portfolios to alternative scenarios, as is needed in stress testing exercises. Indeed, we show that our analysis is a good starting point to evaluate credit risk exposures under stressful conditions, as required under current capital regulation. Furthermore, since the unilateral CVA is roughly the product of the credit derivative expected exposure to a given counterpart and its CDS spread, our estimated global credit risk factor has a great potential for risk management. Indeed, our global credit risk factor can be thought of as a proxy for the CDS spread of an average issuer, so that characterizing the most relevant factors behind the global credit risk factor should be a key element for any treasury department interested in the daily management of CVA risk. The factor model could also be used to project the level of credit risk into a future horizon, either by forecasting trajectories for the factors or by simulating alternative scenarios.

This is very relevant because the European Banking Authority, EBA (2016), requires banks to identify the type of situations, such as economic downturns in the whole economy or in particular sectors, as well as the combinations of credit and market events that could produce substantial losses. Since they also need to define their own approach to evaluate the impact of stress scenarios given by shocks to risk factors coming from economic or industry downturns, market-risk events, and liquidity conditions, the combination of a global credit risk factor and a factor model for its determinants can be a very useful tool.

Estimating the forward-looking, default-related of market CDS spreads may allow for the estimation from CDS spreads of the level of provisions needed to cover credit risk in a given sector, or the level of required capital. They can also provide a reference for pricing a new issue, and they are clearly very useful for asset allocation exercises. Such possibilities remain open for further research.

The paper is structured as follows: In the next section, we review the most relevant literature related to our analysis. In Section 3 we describe our database for CDS spreads as well as for financial and macroeconomic indicators and we estimate sectorial credit indices. In Section 4 we describe the methodology for estimation of the default-related component of CDS spreads, and we estimate our proposed global credit risk factor (GCRF). In section 5 we search for determinants of GCRF, analyze how their importance has changed over time, and examine their relevance over the different quantiles of the distribution of the GCRF. In section 6 we introduce a four-factor model to summarize the types of risk incorporated in the GCRF. In section 7 we show how to use the factor model to perform stresstesting exercises. In section 8 we analyze whether the default-related component of CDS spreads is priced in the credit market. We summarize our analysis in Section 9, suggesting some open questions for further research. 


\section{Review of literature}

The recent literature on measuring systemic risk has grown quite extensively after the financial crisis. In this section we briefly review the two groups of papers that we consider most relevant for our work.

A first group has considered the characterization of an indicator of systemic risk, with the principal component methodology playing a prominent role in that search. Using a sample of 150 European firms from January 2003 to July 2007, Berndt and Obreja (2010) show that the first principal component of CDS returns explained $46 \%$ of the variation in weekly CDS returns, even after correcting for a market factor (weekly excess return on the MSCI Europe index) and a term premium, computed as the spread between the weekly return on the ten-year Euribor bond and the one-week Euribor. Chen and Härdle (2015) found that the first principal component for a set of eight iTraxx and CDX indices for 5and 10-year maturities and investment grade and high-yield ratings explained $58.7 \%$ of the variance in the pre-crisis period, up to $72.3 \%$ of the variance in the crisis period, but only $47 \%$ in the post-crisis period. They also concluded that a four-factor model could provide a good fit to weekly changes in CDS indices, with all factors receiving a significant market price. Rodríguez-Moreno and Peña (2013) analyzed two groups of systemic risk measures when searching for the best systemic indicator over the January 2004-November 2009 sample period. A first group contained indicators related to the overall tension in the market, while a second group was made up by indicators related to the contributions of individual institutions to systemic risk. In a sample of 20 European banks and 13 US banks, they found that the first principal component of CDS spreads performed better as a systemic indicator than measures of market stress. Hammoudeh et al. (2013) examined the behavior of the US 5-year sector CDS spread indices for banking, the financial services and the insurance sector over the period January 2004 to March 2009, suggesting the existence of an important systemic component of credit risk in the three sectors. Puzanova and Düllmann (2013) present an approach for measuring systemic risk and decomposing it into the contributions of individual institutions. To assess the system-wide loss, these authors modelled the banking sector as a portfolio comprising banks' net of capital liabilities, employing a widely used credit risk model to assess the tail risk of such a portfolio. The model inputs were the banks' individual probabilities of default, the size of their net of capital liabilities, and the banks' sensitivity to systemic factors, which capture correlations between banks' asset returns. A piece of work related to ours is Schwaab et al. (2017), where a global risk factor, estimated following a different approach, was detected as a first-order source of default risk variation and default clustering. These authors deduced the existence of a world credit risk cycle on top of world business cycle conditions.

A second strand of literature has attempted to characterize potential determinants of credit risk. Sometimes attention has been paid to accounting data and characteristics of the firm as indicators of credit risk. Blanco et al. (2005) examine the relationship between CDS spreads and equity prices, as well as the relevance of a firm's fundamentals and accounting data to explain variations in CDS 
spreads. Pires et al. (2015) examined the empirical determinants of CDS under a quantile regression approach to analyze the explanatory power in variables such as implied volatility, the put skew, historical stock returns, leverage, profitability, and ratings. The explanatory power of the set of factors was found to increase with CDS premiums, in consistency with the credit spread puzzle. Generally, financial or macroeconomic indicators have also been used, and sometimes their explanatory power is compared with that of individual firm's data. Berndt and Obreja (2010) and Chen and Härdle (2015) analyzed the impact of some financial variables on individual CDS spreads and CDS indices, respectively. Calice (2014) investigated the linkages between the CDS index market and the equity returns of a sample of systemically important financial institutions, uncovering three key findings. First, the equity returns for all systematically important institutions were inversely associated to shocks in the CDS index market. Second, European institutions demonstrated a stronger connection with the iTraxx whilst the US institutions were more closely related to the CDX. Third, US banks were most severely distressed by the volatility transmission mechanism whilst European insurers are least affected. Chun et al. (2014) proposed a model for credit spreads with either endogenous or monetary regimes. They found that market, default, and liquidity factors have superior explanatory power because of their interaction with the regime. Tang and Yan (2010) examined the impact of the interaction between market and default risk on corporate credit spreads. They found that average credit spreads decrease with GDP growth, but they increase with GDP growth volatility and jump risk in the equity market. At the market level, investor sentiment is the most important determinant of credit spreads. At the firm level, credit spreads generally rise with cash flow volatility and beta. They identified implied volatility as the most significant determinant of default risk among firm-level characteristics. Guesmi et al. (2018) used a comprehensive data set of 11 sector indices of the S\&P500 and some financial variables to study their dynamic interaction with industry credit default swaps from mid-December 2007 to the end of December 2016. They attempted to measure the asymmetric long-run and short-run dependence of CDS spreads with respect to their financial determinants. CDS spreads are found to be sensitive to positive and negative shocks in the respective industry stock price as well as to business conditions. Furthermore, the sensitivity of CDS spreads to positive and negative unit changes in the rest of the financial determinants are sector dependent. Pereira et al. (2018) investigated the determinants of corporate credit default swap spreads for US, UK and EU firms. They found that the predictive power of accounting risk measures decreases during and following the crisis, suggesting that the increased relevance of market-based variables highlights the growing significance of forward-looking risk measures for modelling spreads.

Our work is most closely related to Pan and Singleton (2008), Longstaff et al. (2011) and Schwaab et al. (2017), although we focus on somewhat different issues. Longstaff et al. (2011) use a sample of 26 sovereign CDS for the $2000-2010$ period to show that sovereign credit risk is much more correlated across countries than are equity index returns, the source of such commonality being the dependence of sovereign credit spreads on a common set of global market factors, risk premia, and liquidity patterns. We share with these authors the use of Pan and Singleton (2008) methodology to decompose 
market CDS spreads into their risk-premium and their default-related components. We work with 11 sectors and all regions, showing that the strong commonality that Longstaff et al. (2011) show for sovereign credit extends to most sectors, to the point that a single factor can be obtained to represent to a large extent the time evolution of credit risk in the different sectors and regions. Furthermore, we examine the determinants of our global credit risk factor, in parallel with the analysis of Longstaff et al. (2011) for sovereign credit. We also propose a four-factor model that can summarize a good deal of the information provided by a number of economic and financial indicators on the global credit risk factor, and use that model to perform some stress testing exercises. Finally, we show that defaultrelated credit risk is priced in the market.

Particularly interesting is the work by Schwaab et al. (2017), who examine the common dynamic properties of systematic default risk conditions for firms in different countries, industries and rating groups. Their analysis considers a wide array of macroeconomic and financial indicators from different regions and industries that are summarized in a relatively small set of latent variable using a principal component methodology. To characterize the main sources of default clustering, the authors formulate a state-space VAR model for the latent factors, the expected default frequencies (EDF) from a proprietary database from Moody's, and the observed default rates from cross-sectional groups defined for each region, which are assumed to follow an affine process in the latent factors. The statespace model is estimated by simulated maximum likelihood, finding that macro and default-specific world factors are a primary source of default clustering across countries. Interestingly, they show that defaults cluster more than implied by shared exposures to macro factors, indicating that other factors also play a significant role. In particular, bank credit supply and systematic default risk seem to be inversely related. Our work can be seen as complementary of Schwaab et al. (2017), since both study the nature of credit risk, although with a different focus. Schwaab et al. (2017) analyze the share of systematic default risk that can be attributed to world business cycle factors and default-specific factors, estimate their location over time and assess whether default risk cycles fluctuate over time with macroeconomic conditions, without providing a synthetic risk factor. We propose a methodology to estimate a global credit risk factor, examine the relevance of its main determinants over time, use it as a tool for stress-testing exercises, and analyze whether default-related risk is being priced in the credit market. Schwaab et al. (2017) use factor analysis to construct latent factors that can explain time fluctuations in observed default rates. In a sort of dual strategy, we use factor analysis to construct a latent variable to signal the level of default risk, and search among publicly available indicators for its determinants. Both lines of research complement each other to advance significantly in the knowledge of the global nature of credit risk.

\section{The data}

We use the database provided by Markit, the main supplier of CDS prices [Markit (2008) and Markit (2012)], taking CDS spread data at 1Y, 3Y, 5Y, 7Y, and 10Y maturities for senior unsecured debt, with 
2,608 daily observations between January 2006 and December 2015 on approximately 2,500 firms from the 11 mentioned industries and the 13 geographical areas. We select the 760 firms having daily quotes on their 5-year CDS, the most liquid contract, without having been subject to a merger or acquisition. Most of the CDSs have ratings "BBB" or "A". All these prices are composite, which means that for a given restructuring event, firm and currency, they are the average of prices provided by different financial institutions. The sector classification is on ICB (Industry Classification Benchmark), which distinguishes four levels: Industry, Supra Sector, Sector, and Sub-sector, and we work at Markit industry level, which considers 11 industries: energy, basic materials, industrials, consumer goods, consumer services, health care, financials, technology, telecommunication services, utilities, and government. ${ }^{1}$ Finally, Markit identifies 13 different regions: Africa, Asia, Caribbean, Eastern Europe, Europe, India, Latin America, Middle East, North America, Oceania, Offshore, Pacific and Supranational. The best represented sectors are financials, consumer services and industrials, while the regions with a stronger presence in the database are North America, Europe, and Asia.

To derive a fundamental interpretation of some of the estimates we compute throughout the paper, we will use a wide set of daily indicators from the Bloomberg database. For the purpose of interpreting our results, we classify them as pure financial indicators, equity indicators, risk aversion indicators and indicators bearing some relationship with macroeconomic or monetary policy. Some of the relationships of credit spreads with financial market indicators may be short-lived, and they may be lost if we aggregate to monthly frequencies. It would clearly be interesting to analyze the relationship with business cycle indicators, but our interest here is to evaluate what type of indicators have a stronger influence on credit spreads.

Financial indicators: 1) three-month EURIBOR interest rate, 2) three-month EONIA rate, 3) threemonth USD LIBOR Interest Rate, 4) three-month OIS interest rate index, 5) one-year EURO Swap Rate, 6) five-year EURO Swap Rate, 7) ten-year EURO Swap Rate, 8) one-year USD Swap Rate, 9) five-year USD Swap Rate, 10) ten-year USD Swap Rate, 11) one-year JPY Swap rate, 12) five-year JPY Swap rate, 13) ten-year JPY Swap rate. We use the OIS index and the EONIA rate just to construct liquidity indicators, as explained below.

Equity Indicators (the 10 MSCI global equity indices) 14-23): MSCI World/Basic materials, MSCI World/Consumer goods, MSCI World/Consumer services, MSCI World/Energy, MSCI World/Financials, MSCI World/Healthcare, MSCI World/Industrials, MSCI World/Technology, MSCI World/Telecommunication services and MSCI World/Utility.

Risk aversion indicators: 24) USD liquidity risk premium, measured by the absolute difference between three-month LIBOR and the three-month OIS Index. 25) Euro liquidity premium, measured by the absolute difference between three-month EURIBOR and three-month EONIA, both in euros, 26) three-month five-year USD swaption, 27) three-month five-year Euro swaption, 28) the VIX Volatility

\footnotetext{
${ }^{1}$ Government is a category considered by Markit but not included in the Industry Classification Benchmark.
} 
Index, from CBOE, as market expectations of near-term volatility conveyed by S\&P 500 stock index option prices, 29) the VSTOXX Index, as implied volatility in EURO STOXX 50 real-time option prices, 30) implied volatility from option prices for the three-month euro-dollar exchange rate, 31) implied volatility from the 3-month ATM iTraxx Europe Index options, 32) implied volatility from the 3-month ATM CDX North American Investment Grade Index Option. ${ }^{2}$

The term Libor-OIS spread is considered to be a measure of the health of banks because it reflects their views on the risk of default associated with lending to other banks. Indeed, former Fed Chairman Alan Greenspan stated recently that the "Libor-OIS remains a barometer of fears of bank insolvency" [see (Thornton et al., 2009)]. We use 24)-25) as measures of liquidity-premium which may contain information about stress in the money markets [see (Beirne, 2012) and (Blix Grimaldi, 2010)]. The implied volatility of interest rates in 26)-27) captures the market uncertainty on future monetary policy.

Derivative prices contain information about the probability assessment by market participants of the outcome of the underlying asset price upon maturity. Such an information can be extracted using risk-neutral density functions that can provide a forward-looking insight into the risk sentiment of market participants. Indeed, the difference between the risk-neutral and utility-adjusted density function yields a measure of relative risk aversion of the representative investor. Options are forward looking in nature and thus are a useful source of information for judging market sentiment about future prices of financial assets and their dynamics as it has been stressed elsewhere [see (Siegel, 1997), (Campa and Chang, 1998), and (Lopez and Walter, 2000), (Skintzi and Refenes, 2005), (Driessen et al., 2009), (Ornelas, 2019) and (Hui et al., 2013) among any others]. In particular, the VIX and VSTOXX indices are commonly treated as quick and easy proxies for risk appetite, and they are primarily designed to measure market expectations of volatility in the equity market. They are derived from S\&P 500 and Eurostoxx 50 options implied volatilities, which investors buy and sell to change the amount of risk to which they are exposed [see (Illing and Aaron, 2005)and (Blix Grimaldi, 2010)]. Thus, we use implied volatility variables 28)-32) as measures of risk aversion for different assets: interest rates, equity, forex, or credit.

Macroeconomic indicators: 33) euro-dollar exchange rate, 34) dollar-yen exchange rate, 35) 5-year German government yield, 36) yield on 10-year German government bond, 37) 5-year US Treasury Rate, 38) yield on 10-year US Treasury, 39) the 10-year yield on Japan government debt, 40-42) term structure slope, defined as the 10-year, 1-year rates spread, $r_{t, 10}-r_{t, 1}$, in swap rates in US dollar, euro, and yen, 44-45) term structure curvature, defined as $r_{t, 10}-2 r_{t, 5}+r_{t, 1}$, from swap rates in US dollar, euro and yen.

\footnotetext{
${ }^{2}$ The implicit volatilities from 3-month ATM iTraxx Europe Index Option and the 3-month ATM CDX North American Investment Grade Index Option were provided by JP Morgan.
} 


\section{A global credit risk factor based on default risk premia}

\subsection{Estimating the default-related component of spreads}

Jarrow et al. (2005) pointed out that credit investors get a compensation both for changes in the credit environment, as well as for the possibility of a default event, and an interesting contribution in recent literature on risk credit has advanced methods to decompose of CDS spreads into a risk premium and a default-related premium.

Following Pan and Singleton (2008) and Díaz et al. (2013), let us assume that the price of a creditsensitive instrument depends on a set of state variables $X_{t}$ that follow a diffusion process,

$$
d X_{t}=\mu_{x}^{P}\left(X_{t}, t\right) d t+\sigma_{x}\left(X_{t}, t\right) d B_{t}^{P}
$$

where $\mu_{x}^{P}$ and $\sigma_{x}$ are the drift and instantaneous volatility under the actual measure $\mathbb{P}$. Ghirsanov's theorem, with $B_{t}^{\mathbb{Q}}=B_{t}^{\mathbb{P}}+\int_{0}^{t} \Lambda_{t}$ leads to a risk-neutral process for the state variables,

$$
d X_{t}=\left(\mu_{x}^{P}\left(X_{t}, t\right)-\sigma_{x}\left(X_{t}, t\right) d B_{t}^{Q}\right.
$$

where $\Lambda_{t}$ denotes the price of risk, i.e., risk premium per unit of volatility and the drift $\mu_{x}^{Q}$ under the risk-neutral measure is,

$$
\mu_{x}^{Q}=\mu_{x}^{P}\left(X_{t}, t\right)-\sigma_{x}\left(X_{t}, t\right) \Lambda_{t}
$$

We are interested in the excess return or risk premium of the defaultable security. Since the price $P\left(t, X_{t}\right)$ is a function of the state variables, we can apply Ito's lemma under $\mathbb{Q}$ and $\mathbb{P}$ measures, and the risk premium $\varepsilon_{t}$, is the difference of expectations under $\mathbb{Q}$ and $\mathbb{P}$ measures. Pan and Singleton (2008) and Longstaff et al. (2011) have analyzed the distress risk premium in the context of sovereign default swaps. The jump-at-default premium has been studied by Yu (2002), Driessen (2004), Berndt et al. (2005), and Díaz et al. (2013), among others.

Longstaff et al. (2011) and Pan and Singleton (2008) provide the following formula for the price of a CDS contract CDS(M) with maturity M in an intensity based setting, under a default arrival rate $\lambda^{\mathbb{Q}}$,

$$
\frac{1}{4} C D S_{t}(M) \sum_{i=1}^{4 M} E_{t}^{Q}\left[e^{-\int_{t}^{t+.25 i}\left(r_{s}+\lambda_{s}^{Q}\right) d s}\right]=L^{Q} \int_{t}^{t+M} E_{t}^{Q}\left[\lambda_{u}^{Q} e^{-\int_{t}^{u}\left(r_{s}+\lambda_{s}^{Q}\right) d s}\right] d u
$$


We assume that under the historical measure $\mathbb{P}$, the risk-neutral mean arrival rate of a credit event is assumed to follow the log-normal process:

$$
d \ln \lambda_{t}^{Q}=\kappa^{P}\left(\theta^{P}-\ln \lambda_{t}^{Q}\right) d t+\sigma d B_{t}^{P}
$$

where parameters $\kappa^{\mathbb{Q}}, \theta^{\mathbb{Q}}$ and $\sigma$ denote the mean-reversion rate, the long-run mean and the volatility of the process, respectively. This guarantees a positive intensity. Assuming that the market price of risk $\Lambda_{t}$ underlying the change of measure from $\mathbb{P}$ to $\mathbb{Q}$ for $\lambda_{t}$ is an affine function of $\ln \lambda_{t}^{Q}$ :

$$
\Lambda_{t}=\delta_{0}+\delta_{1} \ln \lambda_{t}^{Q}
$$

then, under the risk-neutral measure $\mathbb{Q}$, the logarithm of default intensity $\lambda^{\mathbb{Q}}$ follows an OrnsteinUhlenbeck process,

$$
d \ln \lambda_{t}^{Q}=\kappa^{Q}\left(\theta^{Q}-\ln \lambda_{t}^{Q}\right) d t+\sigma d B_{t}^{Q}
$$

with $\kappa^{Q}=\kappa^{P}+\delta_{1} \sigma$ and $\kappa^{Q} \theta^{Q}=\kappa^{P} \theta^{P}-\delta_{0} \sigma$. To measure the size of the distress risk premium we follow the approach in Longstaff et al. (2011). Any departure between theoretical risk-neutral CDS spreads as given by 4.4 and CDS spreads obtained taking expectations under the $\mathbb{P}$ measure,

$$
\sum_{i=1}^{4 M} E_{t}^{P}\left[e^{-\int_{t}^{t+.25 i}\left(r_{s}+\lambda_{s}^{Q}\right) d s}\right] C D S_{t}^{P}(M)=4 L^{Q} \int_{t}^{t+M} E_{t}^{P}\left[\lambda_{u}^{Q} e^{-\int_{t}^{u}\left(r_{s}+\lambda_{s}^{Q}\right) d s}\right] d u
$$

can be taken as the distress risk premium embedded in CDS spreads.

The model is estimated by maximization of the joint density of the $\lambda^{\mathbb{Q}}$ process and that of a vector of mispricing errors conditional on a given set of parameters. We assume that 5-year CDS are correctly priced, and we make an assumption on a dynamic structure for $\lambda^{\mathbb{Q}}$ conditional on parameters $\kappa^{\mathbb{Q}}, \theta^{\mathbb{Q}}$ and $\sigma$ by inversion of equation 4.4. Mispricing errors at 1-, 3-, 7-, and 10-year CDS contracts are assume to be independent, with zero-mean Normal distributions. We use the US Tbill rate as the risk-free interest rate to discount payments at future maturities. ${ }^{3}$ That leads us to maximizing the

\footnotetext{
${ }^{3}$ Due to lack of observations, for 2006 and 2007 we approximate the one-year rate by an interpolation of the 6-month and 2-year rates. Between December 2007 and December 20008 we interpolate the 3-year rate using the 2- and 5-year rates. During
} 
likelihood function,

$\left.f^{P}\left(\Theta, \lambda_{t}^{Q}\right)=f^{P}\left(\epsilon_{1 y} \mid \sigma_{1}\right) f^{P}\left(\epsilon_{3 y} \mid \sigma_{3}\right)\right) f^{P}\left(\epsilon_{7 y} \mid \sigma_{7}\right) f^{P}\left(\epsilon_{10} \mid \sigma_{10}\right) f^{P}\left(\ln \lambda_{t}^{Q} \mid k^{P}, k^{P} \theta^{P}, \sigma\right) \cdot\left|\frac{\partial C D S^{Q}\left(\lambda_{t}^{Q} \mid k^{Q}, k^{Q} \theta^{Q}, \sigma\right)}{\partial \lambda_{t}^{Q}}\right|^{-1}$

with parameter vector $\Theta=\left(\kappa^{Q}, \kappa^{Q} \theta^{Q}, \sigma, \kappa^{P}, \kappa^{P} \theta^{P}, \sigma_{1}, \sigma_{3}, \sigma_{7}, \sigma_{10}\right), f_{t}^{\mathbb{P}}($.$) being the density of the$ Normal distribution and $\Delta t=1 / 52$. This is the estimation method used in in a similar context by Díaz et al. (2013), following previous work by Berndt et al. (2005) and Longstaff et al. (2011).

Table 1 shows parameter estimates for the 11 sectorial credit indices. Log-likelihood values are similarly high across sectors. Estimated standard deviations for the 1-, 3-, 7- and 10-year tenors oscillate between 6 and 18 bps., which given the size of CDS spreads suggest a good performance of our model. We are using relatively short, sector-specific samples that, even capturing intra-sector variation, do not contain the richer information that we could expect of broader samples. Even though the mean-reversion rate is higher under the $\mathbb{Q}$ than under $\mathbb{P}$, the mean rate of event arrivals itself is much higher under $\mathbb{Q}$, implying that the credit environment is much worse under $\mathbb{Q}$ than under $\mathbb{P}$. This characteristic makes risk-neutral pricing to recover market prices for investors who are averse to default risk.

\section{(INSERT HERE TABLE 1)}

Table 2 (panel a) shows that the median, full-sample default risk premium, the difference between the estimated CDS spread under the $\mathbb{Q}$ and $\mathbb{P}$ measures, is increasing in the tenor. As a percentage of observed spreads, default risk premia are low for the 1-year tenor, and they are relatively stable, between $60 \%$ and $80 \%$ for other tenors. The government and utilities sectors appear with the lowest risk premia, which seems reasonable. The utilities sector is heavily regulated and has a rather inelastic demand, being relatively immune to the crisis. The sovereign sector may have some default risk in a given country, but the expected risk of default for the set of countries included in the sample as a whole should not be too large, especially because most of them are developed countries with an Investment Grade rating. Sovereign sectors from different countries are exposed to contagion, and Longstaff et al. (2011) show that sovereign risk is more correlated across countries than equity indices, but the risk of contagion should have a reflection in CDS spreads more than in the pure risk of default component of spreads.

the 2006-2008 period we approximate the 7-year rate by an interpolation of the 5- and 10-year rates. 


\subsection{Empirical results}

We start by constructing a daily sectorial CDS index for each of the five tenors considered by taking the median CDS spread traded each day in that sector and tenor across firms in all regions. Weekly sectorial data are obtained by taking weekly averages of daily observations for each sector-tenor index. Figure 1 shows the CDS indices for the 5-year tenor, obtained directly from market data. Similar indices were obtained at 1-, 3-, 7- and 10-year tenors, with 366 weekly observations over the 2006-2016 period. Once we apply the estimation strategy described above, the upper panel in Table 2 shows the sample median of the default-related component of spreads for all sectors and tenors. As an illustration, Figure 2 shows the default-related components of the 5 -year sectorial spread indices. Default risk premia started to raise at the outset of the financial crisis, but the sharpest rise arrived at the end of 2008. ${ }^{4}$ By the end of 2009, they started to stabilize at twice their pre-crisis levels, a situation maintained at the end of our sample (beginning of 2016), with no indication of a decrease in the compensation asked by credit investors. However, Figure 4 shows that, as a percentage of the theoretical spread, the risk premium is now lower than before the crisis. Thus, either CDS risk premia has not increased enough to compensate for the increase in credit risk after the financial crisis, or it was too high previous to the crisis. The lower panel in Table 2 shows that, as a percent of traded spreads, risk premia are increasing with the tenor, although with a tendency to stabilize.

\section{(INSERT HERE FIGURE 1)}

(INSERT HERE FIGURE 2)

(INSERT HERE FIGURE 3)

(INSERT HERE TABLE 2)

\section{(INSERT HERE FIGURE 4)}

In a second step, we summarize the information provided for each sector by the default-related components of spread at the 1-, 3-, 5-, 7- and 10-year tenors. The first principal component of these five time series explains more than $90 \%$ of the fluctuation across maturities in all sectors and we take that principal component as the default-related spread index in each sector. Figure 5 shows the sectorial default-related spread indices obtained under this approach. They experienced a substantial increase in January 2008, reaching a local maximum on March 2008. They decreased for a while to start an even sharper increase that took them to maximum values in mid-March 2009. After that, spreads rapidly decreased again, although they did not go back to their low levels prior to the 2007 crisis. The rise of financial CDS spreads in the summer of 2011 due to the European sovereign debt crisis is also clearly visible in the graph.

\footnotetext{
${ }^{4}$ The default risk premium is the difference between the level of theoretical spreads estimated under the the $\mathbb{Q}$ and $\mathbb{P}$ measures.
} 
(INSERT HERE FIGURE 5)

Their main statistical characteristics are displayed in Table 3. Sectorial CDS indices are clearly non-stationary, while their weekly changes are stationary, as it can be confirmed from the application of Dickey-Fuller tests (rows 10-15 in Table 3). The higher volatility is achieved by weekly changes in spreads from telecommunication services and the government sector. Interestingly enough, all sectors display right skewness, while kurtosis is particularly high in the financial, government, health care and utilities sectors. As a consequence, the assumption of normality as the distribution of weekly changes in CDS spreads is overwhelmingly rejected in all sectors.

\section{(INSERT HERE TABLE 3)}

Logarithmic weekly changes in CDS spread indices provide us with a total of 521 weekly observations over the 2006-2015 period. The financial, telecommunication services and government sectors experience the highest volatility. Interestingly enough, all sectors display right skewness. Kurtosis is particularly high in the financial, healthcare and government sectors. Normality is rejected for weekly changes in CDS spreads in all sectors. Sectorial indices are non-stationary processes containing a unit root, whereas the Augmented Dickey-Fuller tests overwhelmingly reject the presence of unit roots in log changes of sectorial indices. Weekly changes in CDS spreads display relatively high correlations across all sectors, reflecting the existence of a common factor with significant explanatory power. Median correlations for each sector are around 0.70, except for healthcare and technology, which have a median correlation around 0.50 , suggesting again the existence of significant specific factors explaining fluctuations in CDS prices in both of these sectors.

\subsection{Estimating a global credit risk factor}

We want to represent systemic risk through an estimated risk factor that incorporates global aspects of risk affecting all sectors and all geographic areas. To capture the high commonality of risk across the different sectors, we resort again to the principal component methodology. The first principal component explains $76 \%$ of the fluctuations in the weekly changes of the 11 sectorial indices, a confirmation that there is strong commonality among the sectors. This is higher than the percentage of variance explained by the first principal component in Berndt and Obreja (2010) using data from European firms during the 2003 to 2008 period, and the explanatory power estimated by Chen and Härdle (2015) for the pre- (58.7\%) and post-crisis periods (72.3\%). Cumulative percentage of total variance explained by the first two principal components is $81 \%$, for the first three it is $85 \%$, and $88 \%$ for the first four. The loadings show that the first principal component is an approximate average of CDS returns over all the sectors, although with a slightly weaker presence of the healthcare and technology sectors. Precisely those sectors with a lower representation in the first principal component, healthcare and technology, dominate the third and fourth principal components, respectively, while the second component is highly correlated with the government sector index. Principal components 
after the first four are much harder to interpret.

Hence, principal components with higher explanatory power after the first one are essentially made up of sector-specific elements. Since a sensible estimate of a global risk factor should avoid embedding elements that mainly affect particular sectors, we will take just the first principal component as the estimate of a latent global risk factor, which we will denote by GCRF, shown in Figure 6, capturing three fourths of the variance in the set of eleven sectorial credit indices. ${ }^{5}$

\section{(INSERT HERE FIGURE 6)}

This decision is consistent with the analysis in Rodríguez-Moreno and Peña (2013). There is also a numerical justification for such a choice: the first eigenvalue is more than 72 times larger than the smallest eigenvalue, while the second eigenvalue is 12 times larger, the third one is 5.4 times, and so on. By construction, our choice of GCRF uses information on the set of CDS spreads trading at each point in time for all firms in the different sectors in all regions. The median R-squared in regressions explaining logarithmic weekly changes in sectorial indices by the GCRF alone is 0.67 , a high explanatory power that also justifies the interpretation of the first principal component as representing a global risk factor. ${ }^{6}$

The evolution of the explanatory power of GCRF gives us an estimate of the global nature of events in the credit market. In so far as the effects of the financial and economic crisis were felt over the whole economy, we should expect to see the GCRF increasing its relevance and dominating sector specific risk elements. To check that hypothesis, we follow Eichengreen et al. (2012) to use annual windows to estimate the percentage of total variance in the set of 11 sectorial index returns that is explained by GCRF (Figure 7). Estimates start the first week of January 2007, running to the end of December 2015 using the sample made up of the 52 previous weekly observations.

\section{(INSERT HERE FIGURE 7)}

At the beginning of 2007, GCRF explained 50\% of the total variation in sectorial CDS indices. The explanatory power sharply jumped from $40 \%$ the last week of June 2007 to $70 \%$ on mid-August, at the outbreak of the sub-prime crisis after the failure of three hedge funds at BNP Paribas. The commonality among all sectors of activity continued on the rise, possibly as a reflection of the perception of risk across the economy, with the explanatory power of GCRF reaching a local maximum of $90 \%$ in March 2008, at the time of the Bear Sterns rescue. In fact, the maintained high commonality of risk since that date could have been taken as an indication of potential future problems well in advance of the Lehman crisis. The commonality in sectorial CDS indices declined from their peaks but remained at the post-Bear Stearns high levels, indicating that risk was widespread across the sectors. These results

\footnotetext{
${ }^{5}$ Novales and Chamizo (2019) estimate a global risk factor working directly from the sectorial credit indices. By not extracting the default-related component of spreads, they assume that observed CDS spreads are compensating for default risk alone.

${ }^{6}$ Being a principal component, the sign of the weights in the linear combination is undetermined. We have defined GCRF to have the same sign as iTraxx. The linear correlation coefficient between them is 0.77 .
} 
are comparable to those obtained by Berndt and Obreja (2010) and Chen and Härdle (2015), among others. A sharp decrease can be seen in the relevance of GCRF in May 2011, at the time of the Portugal bail out, once the EU had decided to allow the European Financial Stability Facility (EFSF) to buy debt in primary markets up to a 440 billion euro ceiling, and had agreed to cut the interest rates and extend the maturities of emergency loans to Greece. The downgrade of US debt on August 5, the deterioration of the economic situation in the US, the alarm over a potentially catastrophic credit crisis in Europe and the downgrade of sovereign debt in southern European countries explain the increase in the relevance of the GCRF in the second part of that year, to levels of $85 \%$ by the end of 2011 . From that point on, the explanatory power gradually decreased to levels of $60 \%$ at the end of 2015 .

\subsection{Estimating alternative indicators of global credit risk}

We also estimate a Corporate GCRF by excluding from consideration the financial and the government sectors, with the result shown in Figure 6. We obtain a striking resemblance between both estimates, with a linear correlation of 0.99. The estimate of GCRF obtained with all the sectors remains higher after 2008, but the pattern of fluctuations over time is the same for both estimates. In both estimates, the 2008 increase became permanent. The similarity between the corporate GCRF and the GCRF estimated with all the sectors is additional evidence in support of our choice of a single principal component to summarize credit risk.

Rather than inferring from Figure 6 that the government and financial sectors play a minor role in the economy. On the contrary, spread risk from sovereigns is clearly one of the main factors explaining the financial sector credit risk as well as that of the remaining sectors of the real economy. Furthermore, transmission mechanisms between the government and the financial sector have been extensively studied in the literature (Acharya et al. (2014) among many others). We believe that the similarity between our estimates of GCRF and Corporate GCRF comes from the large interconnection that there is across the word economy after the globalization. For instance, Ejsing and Lemke (2011) finds a tight connection between single-name CDS from non-financial sectors and CDS spread from sovereign bonds, suggesting that information is transmitted across the economy and across countries almost immediately. Nevertheless, there could be instances when GCRF or Corporate GCRF might contain information different from that in sovereign or financial spreads. Specific problems affecting markets in the real economy as the real estate, markets for basic materials, or a crisis in technological or telecommunications firms because of new innovations could lead to situations the might have a reflection in indicators like the GCRF or Corporate GCRF, without a significant effect on sovereigns or financial spreads.

A limitation of our data set might also explain this result. We have aggregated inside each sector by taking the median spread and thus, the implied sectorial indices do not capture appropriately the size of the assets of firms in the sector. When combining the sectorial indices in the GCRF factor, we again have not used any measure of the size of the firms in the sector, relying in unweighted statistical 
measures. The best alternative would clearly be to include a measure of the total assets of each firm in the data set. A simpler alternative would be to compute directly principal components taking all the firms in the dataset. That way, the sectors with most firms will weigh more heavily in the GCRF indicator. However, this would be looking at the number of firms, not their size.

\subsection{Using daily data}

As explained in the Introduction, we use weekly data in our analysis in an attempt to avoid the non-fundamental volatility that might arise because of low liquidity in daily CDS data. To check our results, we repeated the empirical work using the higher frequency data, obtaining a more volatile GCRF estimate. When explained using daily observations on the economic and financial indicators used in Table 5, we obtain an adjusted R2 of 0.218 , well below the one obtained with weekly data. Most likely, the lower explanatory power is a consequence of the more important noise fluctuations in daily data of both, the economics and financial indicators and also the CDS spreads. In the same vein, the synthetic factor regression achieves an adjusted R-squared of 0.240 , again well below the statistic obtained with weekly data. The more interesting result is that when high frequency fluctuations are reduced by taking weekly averages of the GCRF estimated with daily data, the result is essentially indistinguishable from the GCRF estimated using weekly data.

\subsection{Some evidence on sectorial idiosyncratic components}

The estimated GCRF can be used to obtain a decomposition of a sectorial index in systematic and idiosyncratic components. The fitted term in the regression that explains a sectorial index $I_{t}$ by GCRF,

$$
I_{t}=\beta_{0}+\beta_{1} G C R F_{t}+u_{t}
$$

can be taken as the systematic component of that sector, the residuals of the regression providing us with the idiosyncratic component. The R-squared statistic gives us an indication of the relevance of the systematic component, while 1-Rsquared might be taken as an indication of the relevance of the idiosyncratic component. Table 4 shows the correlations of the default-related sectorial CDS spread indices with GCRF , together with the full-sample estimates of the R-squared statistics from (4.10). ${ }^{7}$ The systemic component will be more important in those sectors where GCRF has a higher explanatory power for sectorial indices, and we can think of those sectors as being systemic in nature, the opposite situation defining the idiosyncratic sectors. Thus, consumer services would be the most systemic sector, together with energy, financial, industrial and telecommunications. The most idiosyncratic sectors are healthcare, technology and government.

\footnotetext{
${ }^{7}$ Of course, the former is the squared of the latter.
} 


\section{(INSERT HERE TABLE 4)}

When we correlate the estimated idiosyncratic components across sectors, 40 of the 55 correlations are below 0.20 , suggesting that the estimated idiosyncratic components do not contain much common information, as it should be expected of such components. An even stronger evidence supporting these estimated idiosyncratic components is that the wide set of indicators used in the paper lack any explanatory power over them. Adjusted R-squared from regressions explaining sectorial idiosyncratic components by the whole set of indicators are all below 0.15 .

We estimated these models using annual rolling windows (52 weekly data points), and Figure 8 shows the difference between the median relevance of the systematic and idiosyncratic components across sectors. The systematic component is clearly more important than the idiosyncratic component over most of the sample, since the difference is positive almost everywhere. Its relevance increased during the financial crisis, reaching a maximum in February 2008. It then started a slow reduction and by May 2011 both components were equally important, but in August of that year, again a sharp increase brought a new maximum relevance of the systemic component by October 2011 . As the credit market perception of risk decreased, the weight of the systemic component came down again and both components were equally important in January 2013 and June 2014. However, this behavior is heterogeneous across sectors and Figure 8 illustrates this by showing the same analysis for the technology and financial sectors. The idiosyncratic component was generally more important than the systemic component in the healthcare and technology sectors. These are also the sectors in which the sample median R-squared of regressions of the sectorial index on GCRF are the lowest, as shown by column 4 in Table 4.

(INSERT HERE FIGURE 8)

\section{Types of risk captured by the global risk factor}

Having estimated a global risk credit factor leads naturally to analyzing the type of macroeconomic and financial indicators that provide information on the evolution of credit risk at a global level. This is the goal of this section. Besides allowing for a real time evaluation of potential stress in credit markets, this type of analysis will also provide us with estimates of the way different credit portfolios might react to macroeconomic and financial events. As in any factor model, the sensitivity of a given firm or a given portfolio can be obtained as the product of the portfolio beta relative to GCRF, multiplied by the sensitivity of the latter to the specific macroeconomic or financial indicator. This yields estimates of the reaction of any given portfolio to different scenarios defined on the risk factors. All we need is information in the form of periodically estimated betas that can be stored, to be used when needed. 


\subsection{Relationship with other risk indicators}

GCRF has been estimated using exclusively credit market data, and our goal is to characterize its determinants in order to be able to anticipate the evolution of credit risk under alternative scenarios for its main sources. But before moving into that exercise, it seems sensible to analyze whether our proposed estimate of global risk is actually able to capture information regarding the situation in the credit market.

To satisfy that requirement, we perform three simple exercises. First, we examine the relationship between GCRF and the speculative grade default rate provided by S\&P (2016). ${ }^{8}$ Since we have annual data for the default rate, we also take annual averages of GCRF. Figure 9 shows the similar evolution over time of both variables, with the exception of 2009. In fact, even with that discrepancy, the linear correlation between them is 0.68 .

\section{(INSERT HERE FIGURE 9)}

A second exercise compares our estimate of the corporate GCRF with the Financial Stress Index (STLFSI) elaborated by the Federal Reserve Bank of Saint Louis. Figure 10 shows a striking similarity in their time evolution. ${ }^{9}$ While GCRF is computed from data on CDS spreads alone, the Financial Stress index is obtained from 18 weekly data series: seven interest rate series, six yield spreads and five other indicators, and each of these variables captures some aspect of financial stress. ${ }^{10}$

\section{(INSERT HERE FIGURE 10)}

It is really encouraging for an estimate that aims at reflecting the level of stress in credit markets to have such a resemblance with an index designed to indicate the level of financial stress that is estimated from a wide set of indicators. Even though their time profile is very similar, the Financial Stress index gave clearer signs in August 2007 of the upcoming financial difficulties, which became clear in GCRF in November of that year. The correlation between their weekly changes over the whole sample is 0.54 . The main difference between them is that while the Financial Stress index returned to its level before the financial crisis, our GCRF remained moderately high. However, this has the sound interpretation that while the level of stress across financial markets can be seen now to be below average, the situation of credit markets is less optimistic.

As a final piece of evidence on the nature of our estimated GCRF we compare its time evolution

\footnotetext{
${ }^{8}$ Following S\&P methodology, all default rates that appear in that study are based on the number of firms rather than the dollar amounts affected by defaults or rating changes. Although dollar amounts provide information about the portion of the market that is affected by defaults or rating changes, issuer-weighted averages are a more useful measure of the performance of ratings.

${ }^{9}$ To make the comparison easier, we have subtracted a constant from the time series for corporate GCRF, so that the initial values for both variables are the same. The overall GCRF displays the same similarity with the Financial Stress Index, but the after-crisis difference between both variables are somewhat wider.

${ }^{10}$ The average value of the index, which begins in late 1993, is designed to be zero. Thus, zero is viewed as representing normal financial market conditions. Values below zero suggest below-average financial market stress, while values above zero suggest above-average financial market stress.
} 
with that of the price of gold, which followed an increasing trend between 2006 and 2012, a good part of our sample period. It experienced a sharp increase, close to 20\%, between August 2007 and March 2008, but its behavior during the financial crisis was not as dramatic as that of the GCRF. Both variables have followed a relatively regular decline since 2012, being at the end of 2015 around their levels of September 2009. Especially in the second part of the sample, since January 2012, both series have followed a similar pattern, including the rise of approximately $20 \%$ in the second semester of 2011 because of the Greek sovereign debt crisis.

\subsection{What are the most influential variables explaining credit spread fluctuations?}

Ericsson et al. (2009) used CDS data on senior debt for individual firms 1999-2002 to confirm the relevance of some theoretical determinants of default risk, such as leverage, market volatility, the riskfree rate, and the actual market premium. They found that these variables explained approximately $60 \%$ of the variation in the levels of CDS premia, with an R-squared for changes in credit default swap premia of approximately $23 \%$. Using transaction data from 2002-2009 covering 861 North American corporates, Tang and Yan (2013) found that CDS spreads were mostly driven by fundamental variables such as firms' volatility and leverage, market conditions as the VIX volatility index, swap interest rates, the term structure slope, stock prices, CDS liquidity as indicated by the bid-ask spread, and investor risk aversion, with excess demand for CDS contracts playing a secondary role. These authors found that even if the level of default risk stays the same, CDS spreads increase when investors become more pessimistic and more risk averse, as reflected in increases in the VIX index. With R-squared estimates around $30 \%$, changes in stock price volatility at the level of firms seem to be one of the main determinants of CDS spreads, with a one standard deviation increase in stock volatility leading to a $12.5 \%$ increase in CDS spreads. This result is consistent with those of Campbell and Taksler (2003), Ericsson et al. (2009) and Zhang et al. (2009).

Our approach and our goal are somewhat different, since we want to explore what underlies the behavior of GCRF by looking at its correlations with market aggregate financial indicators. Such relationships allow for relatively simple ways of analyzing the effect on CDS spreads of different financial scenarios. Considering economy-wide aggregates is also interesting from the point of view of having a simple system to estimate the potential risks in a variety of credit portfolios, as we will see below. After that, in the next section we will also explore the determinants of CDS spreads at the level of sectors, a necessary tool for risk management of sectorial credit portfolios. Besides, such aggregation eliminates most of the noise that appears in individual firm data.

GCRF displays positive correlations, between 0.68 and 0.84 , with weekly changes in all credit indices: iTraxx, CDX, JP iTraxx, HiVol iTraxx, and HY CDX, as expected from its construction as a principal component of CDS spreads across sectors and regions. It is also positively correlated with the two credit market implied volatility indices, VCDX, VITRAXX, and with the stock market volatility indices, VSTOXX and VIX, as well as with the volatility of the euro-dollar exchange rate. GCRF has a negative 
correlation, above 0.35 in absolute value, with German 5-year and 10-year rates, 5-year and 10-year US, euro and yen swap rates, and 5-year and 10-year T-bill rates. It is also negatively correlated with the yield on Japan’s public debt and all the ten MSCI sectorial indices.

Essentially, GCRF seems to capture information from first and second order moments from the credit markets, and it is negatively related to a variety of interest rates, as well as to the stock market, and positively related to volatility indicators. All estimated correlations display the expected signs. An increasing stock market is good news that comes together with a reduction in CDS spreads, as expected. A negative correlation between CDS premia and some interest rates was also documented for bond yield spreads by Longstaff and Schwartz (1995) and also by Ericsson et al. (2009), while the positive correlation with stock market volatility has also been documented when working with single CDS spreads in some of the references mentioned above. Furthermore, GCRF maintains similar correlations, albeit of weaker intensity, with the first and second order lags of most of the mentioned indicators.

We will now structure these correlations in a regression model that might help us to understand the factors that influence the evolution of global credit risk. We want to explain weekly changes in GCRF using weekly changes in the macroeconomic and financial indicators described in Section 3. We do not use credit market indicators, as they contain similar information to that used to construct GCRF, so their explanatory power in such a regression would be tautological. The first regression model in Table 5 shows a relatively high adjusted R-squared statistic of 0.45 . That regression captures the positive relation of GCRF with implied credit market volatility (VCDX) and stock market volatility (VIX). The implied volatility in 5-year US swaption rates (ivswapUS) also enters with a positive coefficient. A higher perception of risk as incorporated in these variables naturally leads to an increase in spreads. The regression shows a negative association of GCRF with a liquidity indicator, the spread between Libor and the overnight rate (libor_ovn), as well as with interest rates like the EONIA rate and the 5year yield on swaps in Japanese yens, and a positive dependence from shorter market rates, like the 1-year swap rate in yens. The negative correlation between CDS premia and interest rates is similar to the result documented for bond yield spreads by Longstaff and Schwartz (1995) and also by Ericsson et al. (2009) when analyzing single name CDSs. This is important for the estimation of wrong way risk, since the standard assumption of independence between interest rates and CDS premia when searching for indicators of the risk exposure of derivatives might then lead to an underestimation of the level of risk. GCRF also decreases when either the slope or the curvature of the USD and euro term structures increase. ${ }^{11}$

\section{(INSERT HERE TABLE 5)}

\footnotetext{
${ }^{11}$ Even though no other indicator would add significant explanatory power to the regressions in Table 5, there might be slightly different subsets of financial and macroeconomic indicators attaining a degree of explanatory power similar to these regressions.
} 
From the point of view of the hedging possibilities of credit positions, this regression suggests that a well-diversified credit portfolio might be hedged by taking appropriate positions in interest rates and volatility derivatives. The same observation would apply to sectorial credit portfolios having an important systemic component of risk. Analyzing the efficiency of such hedging strategies is an interesting question that would merit further research.

Incidentally, the set of macroeconomic and financial indicators we are considering does not have a significant explanatory power for the principal components constructed from sectorial indices beyond the first one, which we have taken as GCRF. All the indicators together explain just $12 \%$ of the fluctuation in the second principal component and $5 \%$ of the third and the fourth components. In particular, this result means that whichever specific component there may be in CDS returns from the government, technology or healthcare sectors, it is not of a financial nature. It might be related to firm characteristics that we have not taken into account in our analysis. This reinforces our decision to stick to just the first principal component to estimate a latent factor that can adequately capture the systemic component of global credit risk.

A further issue is the relevance of the MSCI stock market indices to explain the evolution of GCRF. Column 3 in Table 5 shows that just two of these indices, for basic materials and the financial sectors, achieve by themselves an adjusted R-squared similar to the regression on financial and macroeconomic indicators. These indices can also be used to complete the regression on the financial and macroeconomic indicators, as shown in the third column of the table, with an adjusted R-squared statistic of 0.53 . The high explanatory power of MSCI indices can be explained from the fact that our estimate of the GCRF is obtained from unsecured senior debt, so that a fall in MSCI indices can be perceived as an increase in the systemic risk of a broad-based default of firms. These two regressions can be combined as shown in column 4 , to achieve an adjusted R-squared of 0.53. A search for regression models to explain the time evolution of the corporate GCRF led to an specification and an explanatory power very similar to those shown for GCRF (last column in the Table 5).

Figure 11 shows the evolution over time of the R-squared of the first two regressions in Table $5 .{ }^{12}$ As we can see, the explanatory power of the two MSCI sectorial indices is important. In fact, over 20122014 , their explanatory power is even higher than that of the set of indicators used in the first regression in Table 5. The Lehman Brothers bankruptcy in August 2008 drastically increased the explanatory power of either set of indicators. Their relevance in explaining credit risk diminished after February 2011 , to increase steadily again in July of that year. Their explanatory power gradually decreased again after November 2012. After some gain in explanatory power during 2014, the information of the MSCI decreased throughout 2015, suggesting a decoupling of the credit and equity markets during that year.

\section{(INSERT HERE FIGURE 11)}

\footnotetext{
${ }^{12}$ They appear with the labels 'Indicators' and 'MSCI'. We describe below the information presented under the label 'Synthetic factors'.
} 


\section{A factor analysis approach}

To further clarify the relative importance of the different indicators in determining the time evolution of GCRF, we specify in this section a factor model summarizing the information in the set of indicators described in section 3. We want to construct a latent factor for each of the four groups of variables: MSCI equity indices, macroeconomic, risk aversion, and financial indicators. The goal of this section is in line with recent work by Schwaab et al. (2017) who use a latent factor methodology to characterize global and regional macroeconomic factors as well as global, regional and industry-specific default factors. The estimated factors are then used to characterize the determinants of observed default rates across regions, sectors and industries, as captured by the expected default frequencies (EDF) by Moody's. As these authors, we are interested in searching for determinants of default risk, but we take our default-related global credit risk factor (GCRF) as the main credit risk indicator, while they work with actual default data.

We will choose as synthetic factor the first principal component in each group of indicators, to summarize the information provided by that group. The percentage of the variance explained by such factors is $84 \%$ among the group of MSCI indices, $65 \%$ of the variance of risk aversion indicators, $67 \%$ of the variance of macroeconomic indicators and $59 \%$ among the financial indicators. The latter may be considered a bit low, but the results we obtain in the section do not change noticeably if we consider two latent factors in this group of variables and we prefer to maintain the minimum number of such variables. The equity synthetic indicator is an approximate average of all sectorial MSCI indices. It has a correlation above 0.75 with all sectorial MSCI indices except healthcare and thus, it captures the general evolution of stock prices. Its highest correlations are those from the energy and basic materials sectors. The synthetic risk factor has its highest correlations with the US and Euro threemonth five-year swaption rates. Its correlations with stock market volatilities or credit or exchange rate volatility are much lower. The macro synthetic indicator essentially captures a positive dependence from interest rates on Government bonds from US and Europe as well as from term structure slopes. ${ }^{13}$ Correlations of this synthetic indicator with exchange rates and term structure curvatures are much lower. Finally, the synthetic financial indicator essentially captures risk in medium- and long-term swap rates in the US and Europe.

To examine the explanatory power of this set of synthetic factors, we estimate by least-squares a regression model,

$$
G C R F_{t}=\beta_{0}+\beta_{1} F_{m s c i, t}+\beta_{2} F_{\text {risk }, t}+\beta_{3} F_{\text {macro }, t}+\beta_{4} F_{\text {finan }, t}+u_{t}
$$

\footnotetext{
${ }^{13}$ The correlation with the latter is negative.
} 
having the four synthetic factors as explanatory variables, with the result shown in Table 6 . To make coefficient estimates comparable, we have standardized the synthetic indicators by subtracting their sample mean and dividing by their standard deviation.

\section{(INSERT HERE TABLE 6)}

Thus, it is not surprising that the estimated coefficients on the equity factor and macroeconomic factors are negative, while those on the risk aversion factors are positive. Bull periods in stock markets reduce the probability of default and CDS spreads. Strong economic growth comes together with policy rates on the rise (so, a higher macro factor), and lower CDS spreads. An increase in the risk aversion factor (that is, on implied volatilities) means a higher perception of future uncertainty, and increased CDS spreads. Estimated coefficients on the financial factor are mostly negative but the estimated coefficients are rarely statistically significant.

Using the full 2006-2015 sample, the adjusted R-squared is 0.40. Across sectors, R-squared values are somewhat lower, especially for healthcare and technology that, as already explained, are the least systemic sectors. This is interesting, since it shows that the wide set of indicators that we have considered has some power to explain the evolution of systemic credit risk, while the non-systemic components of credit risk are due to specific sectorial aspects that are unrelated to standard financial and macroeconomic indicators. An interesting open question would be to analyze the evolution over time of the nature of credit risk in each sector, estimating the extent to which risk is systemic. That should be a key input when establishing the sectorial asset allocation policy in a financial institution, a central part of its risk appetite framework.

The stock market synthetic indicator has the largest effect on credit indices in most sectors. The sample mean of the time-varying coefficients in Figure 12 is also largest for the MSCI risk factor. This is an important outcome, as it seems that the equity market performs as a subordinated debt market in times of crisis. Thus, it could be thought of as a natural hedge for the debt market, with the advantage that the equity market is very liquid. The problem for a financial institution is that under the current regulation this type of hedge would be penalized by sharply increasing capital requirements. Hence, addressing the convenience of this particular regulation seems an interesting open question.

\section{(INSERT HERE FIGURE 12)}

The time evolution of the explanatory power of the synthetic indicators for GCRF is shown in Figure 11 together with the explanatory power of the regressions in Table 6, using a rolling window of 52 weeks. The synthetic indicators show an explanatory power similar to the MSCI indices, and it is striking that it even exceeds sometimes the explanatory power of the set of economic and financial indicators. Figure 12 shows the coefficient estimates on the four synthetic indicators using a rolling window of 104 weeks, to cover two years. ${ }^{14}$ All the estimated coefficients maintain their sign for most

\footnotetext{
${ }^{14} \mathrm{~A}$ one-year window renders very volatile estimates.
} 
of the sample: the stock market and macroeconomic risk factors with negative coefficients, the risk aversion and financial factors with positive coefficients. However, the relative importance of the different synthetic indicators changed significantly over time. In the aftermath of the crisis, after 2008, the risk aversion factor was the most important factor for credit risk, with the macro, equity and financial factors taking over through 2010. The equity risk factor (MSCI) is very relevant over most of the sample, losing some importance towards the end. The yield curve was very relevant for credit risk in 2011 and also between mid-2014 and mid-2015, as shown by the large absolute value of the coefficients in the financial and macroeconomic risk factors.

The results of this analysis are again very similar to those obtained when explaining the time behavior of the corporate risk factor. ${ }^{15} \mathrm{R}$-squared and estimated coefficients from regressions explaining the corporate risk factor using the four synthetic indicators as explanatory variables, which are not shown in the paper, are barely different from the ones reported above for the GCRF.

\subsection{Estimating the information content of financial indicators in stressed times}

It is important to consider the possibility that the information content of the factors for global credit risk characterized in the previous section could be contingent on the market situation. Some indicators may become either more or less relevant in stressed times, and taking into account such a distinction might lead to very different inferences on credit risk. Since GCRF is computed from weekly differences in sectorial credit indices, stress periods will be periods when CDS spreads widen, while tranquil periods will be times of contracting CDS spreads. Hence, quantile regression is an appropriate tool for such analysis. As we mentioned in Section 2, Pires et al. (2015) performed a quantile regression analysis on firm-specific determinants of CDS spreads, to find that their explanatory power generally increases with CDS premiums, in consistency with the credit spread puzzle.

We restrict our attention to the four factors characterized above, in an attempt to find out whether their relevance may be different in stressed periods than in calm periods. Table 7 shows quantile regression estimates of the factor model for GCRF, for quantiles between $\mathrm{q}=0.10$ and $\mathrm{q}=0.90$. Figure 13 displays the quantile estimates together with the $95 \%$ confidence bands. The equity factor is relevant over the whole distribution of GCRF, but its importance increases when in the tranquil (low GCRF values) and stressed periods (large GCRF values), indicating that a bull stock market is good news for the credit market anytime. The importance of the risk aversion factor increases at stressed times, an anticipation of higher volatility being bad news for the credit market. The macroeconomic factor is relevant in calm periods, a raise in policy rates of interest then being good news for credit. The financial sector (market interest rates) has a positive effect on CDS spreads in calm periods, shifting to a negative effect at stressed times. It means that an interest rise is interpreted as bad news when markets are relaxed, but it is seen as good news when markets are under stress.

\footnotetext{
${ }^{15}$ That is, the estimate of the GCRF excluding the government and financial sectors.
} 
(INSERT HERE TABLE 7)

(INSERT HERE FIGURE 13)

The last two rows in Table 7 show the values of the F-statistic to test the null hypothesis that each of the coefficients takes the same value for the two quartiles: $q=0.20$ and $q=0.80$, and their $p$-value. The joint test of equality of the vector of coefficient estimates for those two quartiles has a test statistic of 2.22 with $(4 ; 1034)$ degrees of freedom and p-value of 0.065 .

\section{Stress testing sectorial credit portfolios}

Our four-factor model can be used to estimate the effect on CDS spreads of a stress scenario, which we will define as a six-standard deviation simultaneous change in each factor in the direction leading to an increase in CDS spreads. ${ }^{16}$ However, since the synthetic factors are not orthogonal, it would be unrealistic to assume that they change independently in the direction of producing the bigger loss. To avoid that, we use orthogonalized factors using the Cholesky decomposition of the variance covariance matrix among the four factors, ordered as in the regression in Table 6. That means that each factor is substituted by the residual from a regression of that factor on the factors that precede it in the order. Thus, we will estimate,

$$
I_{t}=\beta_{0}+\beta_{1} F_{1 t}+\beta_{2} \tilde{F}_{2 t}+\beta_{3} \tilde{F}_{3 t}+\beta_{4} \tilde{F}_{4 t}+u_{t}
$$

where $I_{t}$ denotes either the weekly changes in the GCRF indicator or in any of the sectorial credit indices, $\tilde{F}_{2 t}$ is the residual from: $F_{2 t}=\alpha_{0}+\alpha_{1} F_{1 t}+\varepsilon_{t}, \tilde{F_{3 t}}$ is the residual from: $F_{3 t}=\alpha_{0}+\alpha_{1} F_{1 t}+$ $\alpha_{2} F_{2 t}+\varepsilon_{t}$, and $\tilde{F_{4 t}}$ is the residual in: $F_{3 t}=\alpha_{0}+\alpha_{1} F_{1 t}+\alpha_{2} F_{2 t}+\alpha_{3} F_{3 t}+\varepsilon_{t}$. A different order of factors in the Cholesky decomposition would amount to a different order of factors in these regressions. We compute the level of increase/decrease in CDS spreads by,

$$
\text { Effect }=6 \sum_{i=1}^{4}\left|\hat{\beta}_{i}\right| \hat{\sigma}_{\tilde{F}_{i}}
$$

where $\hat{\sigma}_{\tilde{F}_{i}}$ denotes the standard deviation of each orthogonalized factor, and $\hat{\beta}_{i}$ are the estimated coefficients from (7.1).

\footnotetext{
${ }^{16}$ Dempster (2002) considers a 3.5 standard deviation change. The stress test at the Bank of Japan BoJ (2007), assesses the impact of a negative GDP shock of a size that has a 1 percent probability. Jiménez and Mencía (2009) apply a three-standarddeviation shock to the GDP and interest rate variables; similarly, Castrén et al. (2009) use a five-standard-deviation shock for a macroeconomic factor. Alexander (2009) considers six standard deviations. In any event, the effect of a change of any given size can be obtained from our estimates applying the appropriate scale factor.
} 
The first two columns in Table 8 show the largest increase in CDS spreads observed in our sample in a single week and the standard deviation of weekly changes in CDS spreads. The third column shows that the estimated effect of the stressed scenario on GCRF when we use the whole sample is 22.7 bps., below the observed sample maximum of 32.1 bps.. Since the sample standard deviation of GCRF is 4.0, the mentioned effect amounts to a 5.7 standard deviation shock. It would be interesting to decompose the effect of the stressed scenario across the four factors, but such decomposition is conditioned by the order followed in the orthogonalization of the factors. However, the total effect of the stress test on either GCRF or on any sectorial index is invariant to the order chosen in the Cholesky decomposition. ${ }^{17}$

\section{(INSERT HERE TABLE 8)}

In practical applications of this stress test procedure, it might sound sensible to assess the impact of a stress scenario on a given credit portfolio as the product of the GCRF beta of that portfolio and the sensitivity of GCRF to the stress scenario. This would avoid the need to estimate the factor model for each portfolio. The last column of the table shows that this approximation works relatively well except for the financial sector, so it may be considered as a reasonable alternative when estimating the level of default-related risk of a number of CDS portfolios.

To evaluate our factor model as a basis to perform stress tests, we consider seven episodes of a different character: 1) the sub-prime crisis: New Century Financial bankruptcy (4/2/2007), Bear Sterns difficulties in July, cease of activity in three hedge funds at BNP Paribas in (8/9/2007), 2) Lehman default: Nationalization of Northern Rock (2/17/2008), Bear Sterns absorption by JP Morgan Chase (3/16/2008), bail out of Fanni Mae and Freddie Mac (9/7/2008), Lehman Brothers bankruptcy (9/15/2008), 3) US Stimulus Act (February 2009), fiscal expansion commitment by London G20 (4/2/2009), 4) Eurozone crisis: Downgrade of Greek debt ( 4/27/2010), Ireland bail out (11/28/2010), 5) EU measures against the crisis: The EU summit expands powers of the European Financial Stability Facility (3/11/2011) , EU finance ministers increase the bail out ability of the ESM (3/21/2011), The ECB bailed out Portugal (5/5/2011), 6) Rating downgrades: S\&P cut Greece rating to CCC (6/13/2011), S\&P downgraded US sovereign debt (8/5/2011), the ECB offers banks unlimited dollar loans for three months (9/15/2011), S\&P cut Italy's credit rating (9/19/2011), Fitch cut Spain and Italy rating (10/7/2011), 7) (7/26/2012) ECB president Draghi unexpectedly gives a strong defence of the euro.

Panel a) of Table 9 shows the actual increases/decreases in CDS spreads observed over each period. Changes in GCRF were small during the sub-prime crisis, reflecting the fact that the market underestimated the depth of the upcoming crisis. The Lehman crisis produced a large increase in GCRF while the US Stimulus Act was able to reduce the default-related component of risk significantly, The rating downgrades in 2011 increased spreads while the Draghi intervention in favor of the euro was effective in reducing risk. Panel b) shows the fitted values of the increase in CDS spreads when we use in 7.2 co-

\footnotetext{
${ }^{17}$ Because of the properties of the least-squares estimator under data transformation by orthogonal matrices.
} 
efficient estimates and factor standard deviations using just the data from each period. Our in-sample estimates replicate quite closely the structure of the variations actually experienced by the GCRF risk index. The lower impact estimated for the second and third periods can be explained by the coincidence in such periods of several stress events whose effects should be accumulated. Overall, the fit of the model is quite good as shown by Figure 14 which compares the actual and estimated changes in spreads across the 11 sectors for the seven periods. The correlation coefficient between observed and fitted changes in spread is $85 \%$, with the straight line indicating that even though the model misses some of the size of the stress effects, it captures the sector-specific sensitivity to the four risk factors.

\section{(INSERT HERE TABLE 9)}

\section{(INSERT HERE FIGURE 14)}

When we perform a purely ex-ante forecasting exercise, estimating factor sensitivities and standard deviations with the information available at the beginning of each period, the fit of the model is clearly not as good, and the correlation between observed and fitted effects lowers down to $73 \%$, remaining sufficiently high to suggest that this factor model can be a very useful tool to update the level of capital provisions for credit portfolios, ${ }^{18} \mathrm{~A}$ real-time use of the model would improve upon this by updating model estimates as new data on a possible stress period is received. Indeed, using the information available at each point in time in the form of a 52-week rolling window sample to obtain an estimate of the expected increase in CDS spreads under a stress scenario, we obtain the result shown in Figure 15. As the financial crisis developed, the factor model drastically raised its estimate of the potential increase in GCRF in a stress scenario. The estimated increase remained high even for some time after CDS spreads themselves decreased. The factor model gradually raised its estimate of the potential increase in spreads in an stress scenario at the time of the European sovereign crisis, staying high for some time after the crisis had receded. Overall, the pattern of variation of the estimated effects of a stress scenario seems reasonable, being almost 10 times higher at the peak of the crisis than at the end of our sample, in December 2015.

\section{(INSERT HERE FIGURE 15)}

This analysis suggests the convenience of considering quantile regressions when using a factor model of this kind to anticipate stress effects in GCRF, since we shown above 7 that estimates of the factor model are sensitive to market situations, and this should be expected to lead to potentially significant differences when estimating the level of credit risk. As an illustration, if we use the orthogonalized factor model at the $\mathrm{q}=0.25$ and $\mathrm{q}=0.75$ quartiles to compute the impact on GCRF of a six standard deviation in each of the factors over period 2, we obtain an increase of $102.9 \mathrm{bps}$. when $\mathrm{q}=0.20$, and an increase of 122.4 bps. when $\mathrm{q}=0.80$ (almost $20 \%$ higher), which amount to effects of 3.1 and 3.7 standard deviations, respectively. As we can see, the effect in stressed periods is significantly

\footnotetext{
${ }^{18}$ We have estimated the factor model with a one-year sample previous to the beginning of each period (52 weekly observations)
} 
higher, showing the importance of taking into account these differences when drawing inferences on credit risk. Indeed, using the factor sensitivities estimated with the whole sample, which can be seen as an approximate average of the quantile estimates of factor sensitivities, we obtained in Table 8 an expected increase of 75 bps., well below the one estimated for either $\mathrm{q}=0.20$ or $\mathrm{q}=0.80$.

Overall, the use of a synthetic factor model for the global credit risk factor for stress testing exercises seems to be a research avenue that deserves further consideration. We have just run a one-week stress test exercise, but longer term horizons could also be considered, and risk management under current regulation asks for stress tests at medium-term horizons. Predicted time paths for the synthetic factors could be obtained from estimated univariate models or from a vector autoregression model. Alternatively, they could be chosen to define a given scenario of interest on which to condition the stress test. Then the synthetic factor regressions above could be used to generate a trajectory for GCRF. Given any credit portfolio, its beta with respect to GCRF could finally be used to obtain a time series for the portfolio credit spread. The stochastic components in the forecasting models for the synthetic factors, the synthetic factor regression for GCRF, and the relationship between the portfolio credit spread and GCRF could be used to obtain a large number of trajectories for the portfolio credit spread at the required horizon. That would allow us to obtain its empirical probability distribution and perform any desired evaluation, like VaR, Expected Shortfall, or the probability of the portfolio credit spread taking a value in any specific range. We leave the detailed analysis of this computational possibility as an interesting matter for further research.

\section{The market value of the Global Risk Factor}

A fundamental issue refers to whether or not systemic risk was priced in the market during our sample period. In the absence of any market value, investors would undervalue the actual level of risk, possibly leading to a credit expansion with the abuse of the standard credit principles, as occurred before the sub-prime crisis, with devastating consequences for the real economy. ${ }^{19}$ Claußen et al. (May 2017) who already analyzed the pricing of systemic risk factors using information from credit default swap contracts from 339 U.S. entities from 2004 to 2010, controlling for individual risk factors such as credit ratings, liquidity and leverage. They found that their basic risk factors explain about $83 \%$ of the CDS spreads prior to the crisis and about $90 \%$ during the crisis. In this section we analyze whether the default-related component of risk is priced in the market, following two different strategies: First, comparing the time behavior of spreads in CDS portfolios constructed on the basis of the GCRF betas of individual firms. Second, by running a Fama-Macbeth type of estimation exercise of CDS spreads on a number of portfolios, Fama and MacBeth (1973).

Our sample is composed by the 760 firms that had a quoted price for the 5 -year senior unsecured

\footnotetext{
${ }^{19}$ See, for instance, Ivashina and Scharfstein (2010)
} 
CDS every day during the period 2006-2015. ${ }^{20}$ Since these are CDS contracts from all geographical areas, we take as the credit market index the average of iTraxx and CDX.

Our first strategy for analyzing the market price of risk is based on univariate sorting. We sort the 760 individual CDS contracts into different portfolios according to the sensitivity of their weekly percent spread change with respect to GCRF, and the cross-sectional performance of these portfolios will be indicative of the price of risk associated to GCRF. We form 8 equally weighted portfolios including 95 CDS contracts in each portfolio. The first portfolio has the lowest sensitivity to an innovation in GCRF, with the last portfolio having the highest sensitivity to that risk factor. We also consider the portfolio that is long in portfolio 8 and short in portfolio 1 . We estimate least-squares betas relative to GCRF using a window of 52 weeks to cover a whole year. After portfolio formation, we record the spread change over the next 52 weeks. At that point, we use those 52 weeks to estimate the betas again and form new portfolios and register their spread changes over the next 52 -week period. This way we estimate betas and construct portfolios at the beginning of each year between 2007 and 2015, recording their spreads at the end of the year. If the innovation in GCRF is a priced risk factor, we should see a monotonic pattern in average spreads for portfolios sorted on their exposure to innovations in the risk factor.

Table 10 shows average weekly spread changes for each portfolio, their annualized values, and the average beta for each portfolio. Even though they are not strictly monotonic, average portfolio spread changes seem to indeed increase with the sensitivity to GCRF, suggesting that the credit market prices the exposure to the type of risk embedded in GCRF. Furthermore, the estimated value is large: while credit portfolios with low betas display moderate increases in spreads through our sample, portfolios with a high exposure to GCRF risk have a very significant average deterioration in spreads. It is interesting that the portfolio made up by CDS contracts with the lowest GCRF betas also has a relatively high average weekly spread change. These results suggest that exposure to GCRF risk by individual CDS contracts should be a very relevant consideration when forming CDS portfolios. ${ }^{21}$

\section{(INSERT HERE TABLE 10)}

Our second strategy to estimate the possible market price of GCRF risk is to follow the Fama and MacBeth approach. Portfolios are formed by sorting individual CDS spreads on the basis of their beta sensitivity to the credit market proxy, which will again be the average of the iTraxx and CDX indices. We distribute the 760 firms into 38 portfolios according to their market beta. All portfolios are made up by 20 firms. Market betas are estimated by least squares in the regression,

$$
C D S_{j t}=\beta_{j 0}+\beta_{j m} \text { Market }_{t}+\varepsilon_{j t}, j=1,2, \ldots, 760,
$$

\footnotetext{
${ }^{20}$ For instance, Banco Santander is not included in the European financial sample as it changed its corporate name from Banco Santander Central Hispano to Banco Santander on 13 August 2007, consequently changing its company ticker.

${ }^{21}$ Since weekly spread changes have positive skewness, median spread changes for the eight portfolios would be negative, but they would still show a nearly monotonic dependence from the sensitivity to GCRF risk.
} 
The first portfolio is made up by the firms with the lowest sensitivity to the credit market index, while the last portfolio contains the CDS spreads with the highest sensitivity to the credit index. We are interested in the model: $r_{i t}-r_{f t}=\beta_{i, 0}+\beta_{i m}\left(r_{m t}-r_{f t}\right)+\beta_{i, G C R F} G C R F_{t}+u_{i t}, i=1,2, \ldots, 38$, for a given time period $t$, where $r_{i t}-r_{f t}$ denotes the difference between the percent weekly change in CDS and the weekly risk-free return, $r_{f t}$, for which we take the 3-month US interest rate. The time series for market returns, $r_{m t}$, is obtained as the difference between the percent weekly change in the credit index and the weekly equivalent of the 3-month US rate. The choice of credit index and the construction of GCRF are as explained above.

The first step of the estimation procedure consists of a set of 38 time series regressions with the same explanatory variables and a different dependent variable. We estimate this regression model for each portfolio using annual rolling window samples, to obtain time series of parameters for each portfolio: $\left(\beta_{i 0, t}, \beta_{i m, t}, \beta_{i, G C R F, t ;}\right), i=1,2, \ldots, 38 ; t=52,53, \ldots, T{ }^{22}$ After that, we estimate a cross section regression: $r_{i t}-r_{f t}=\lambda_{0, t} \beta_{0}+\lambda_{m, t} \beta_{i m t}+\lambda_{G C R F, t} \beta_{i, G C R F, t}+\varepsilon_{i}, i=1,2, \ldots, 38$ using the parameter estimates for the 38 portfolios for each given week. The $\lambda_{m}$ and $\lambda_{G C R F}$ parameters measure the extent to which CDS spreads depend on the betas associated to two risk factors, the market and GCRF. They do not measure whether CDS spreads depend on the risk factors, which is obviously true in the case of the market factor, but rather, whether they depend on the beta sensitivity of the portfolio's return to each factor. Hence, the $\lambda$ parameters can be naturally interpreted as the price of each risk factor. The final estimates of $\lambda$ are obtained as the average of the estimates obtained over the sample: $\bar{\lambda}_{0}=\frac{1}{T-51} \sum_{t=52}^{T} \lambda_{0, t}, \bar{\lambda}_{m}=\frac{1}{T-51} \sum_{t=52}^{T} \lambda_{m, t}, \bar{\lambda}_{G C R F}=\frac{1}{T-51} \sum_{t=52}^{T} \lambda_{G C R F, t}$, and we test for the statistical significance of each $\lambda$-estimate.

Table 11 displays estimates for the market price of zero-beta risk, $\lambda_{0}$, the market price of market beta risk $\lambda_{m}$, and the market price of GCRF beta risk, $\lambda_{G C R F}$. For comparison, Panel a shows estimates when the credit market factor is used by itself, while Panel $b$ shows estimates for both risk factors, the credit market and GCRF. In each case, we show estimates for the whole sample as well as for two regimes, characterized as low and high volatility, those being the periods when the volatility of innovations in the market index are either below or above their median value. ${ }^{23}$ Our estimates suggest that the credit market beta-risk is priced in the market in the lower volatility regime. The same result arises when we introduce in the model the CGRF beta-risk, which is also priced in the market in the low volatility regime. Thus, the market premia seems to come from the tranquil periods, since for the high volatility periods, the market premium for both risk factors decreases substantially and it is not statistically significant. That means that in stressed periods, idiosyncratic characteristics dominate in the market determination of CDS spreads. It is also important to bear in mind that we are not estimating the dependence of portfolio CDS spreads on the market and GCRF factor but rather, their dependence on the betas with respect to these factors. Lack of significance does not mean that CDS spreads do not

\footnotetext{
${ }^{22}$ Estimation starts at week 52, since we use rolling window samples of 52 weekly observations, so as to cover a full year.

${ }^{23}$ Innovations in the market index were estimated from a third order autoregression.
} 
depend on the market index or GCRF, but only that a greater sensitivity of the CDS portfolio to either one of these factors does not necessarily come together with a larger CDS spread. The zero-beta risk does not get any market value, as reflected in the estimate of $\lambda_{0}$. Panel c displays estimates excluding government and financial sectors, which can be seen not to be qualitatively different from estimates obtained with all the 760 firms in our sample.

\section{(INSERT HERE TABLE 11)}

Figure 16 shows observed and fitted weekly average spread changes for the 38 portfolios, using full sample estimates, from these two last models with a correlation between observed and fitted spreads of 0.78 .

\section{(INSERT HERE FIGURE 16)}

The negative sign in $\lambda_{G C R F}$ is to be expected: being associated to higher volatility or lower interest rates, an increase in GCRF signals an increase in CDS spreads. Hence, to reduce the exposure to such a scenario, an investor would like to include in his/her portfolio CDS contracts whose spreads tend to rise the least when GCRF increases. That implies a high demand for CDS contracts with a lower $\beta_{G C R F}$. That will put some upward pressure on their current spread so that their percent weekly change $r_{i t}$ will tend to be high.

Incorporating Fama-French factors to the model does not change much the qualitative results, as shown in Panel d of Table 11. The price of GCRF beta-risk is reduced by the introduction of the new factors although it remains statistically significant, while the price of credit market beta-risk decreases slightly. Both prices remain significant just in the low volatility regime. Only the the stock market beta-risk receives some additional return to that already received by the level of credit market betarisk and GCRF beta-risk assumed by the portfolio. Its estimate is not statistically significant because of a reduced precision (high standard deviation), probably because of the correlation of the stock market excess return factor with $r_{m t}-r_{f t}$ and GCRF.

The fact that the risk embedded in the GCRF is priced in the market suggests that there are no incentives for investors to undervalue this type of risk. This greatly reduces the possibility that credit portfolios might assume an excessive risk exposure, which could be the basis for a further potential instability crisis in the global credit markets.

\section{Conclusions}

We propose a simple two step procedure to estimate a global risk factor using daily CDS spread data from all firms from the different sectors and geographical regions. For each of the five tenors considered (1-, 3-, 5-, 7-, and 10-year) CDS spreads from single names in the same sector from all regions are first consolidated in a sectorial spread index for that tenor, and weekly aggregates are ob- 
tained. Since a global credit risk factor should be based just on the default-related component of CDS spreads, we have applied the methodology developed by Pan and Singleton (2008) to estimate the default component of CDS spreads in each sectorial index for each tenor. The first principal component of the indices obtained for the five tenors in a given sector provides us with a sectorial default index. Finally, the first principal component of such sectorial indices defines the default-related global risk factor (GCRF).

Our estimated GCRF factor offers a broad representation of the global credit markets, explaining $65 \%$ of the variance of the set of 11 sectorial credit indices over the 2006-2015 period. The explanatory power of the GCRF is shown to sharply increase in periods of market stress and decrease in calmer periods. It contains more information than credit indices like iTraxx or CDX on sectorial credit indices. In particular, it seems to capture information on interest rates and implied volatility that is not reflected in standard credit indices.

In spite of being estimated from CDS data alone, GCRF maintains close correlations with the Financial Stress Index elaborated by the Federal Reserve Bank of Saint Louis from a variety of macroeconomic and financial indicators. Even though both display similar time profiles, at the end of our sample (2016) the Financial Stress Index had recovered the level it had before the financial crisis, at a difference from GCRF, suggesting that the level of stress in global credit markets remained significant. GCRF is also correlated with the annual North American corporate speculative-grade default rate as well as with gold prices. It is positively correlated with forward-looking indicators of risk, as volatility indices or implied volatility variables. MSCI stock market indices show a high and negative correlation with GCRF, which is constructed on CDS data alone. GCRF is also negatively associated with the interest rates used for monetary policy, as well with the term structure slope. The negative correlation between CDS premia and some proxies of the risk-free rate runs against the standard assumption of independence between these variables and may be an example of wrong-way risk, leading to an underestimation of the level of risk. Without the obvious recourse to credit indices, we have presented alternative regression models explaining up to $50 \%$ of the fluctuations in GCRF. Furthermore, we have shown that the sensitivity of GCRF to risk aversion indicators becomes stronger as we move from calmer periods to stressed periods. The sensitivity to policy rates and other macroeconomic-oriented indicators is stronger in the more tranquil periods. Even more interestingly, a rise in market interest rates (swap rates, 3-month rates) is interpreted negatively in calm periods, leading to increased CDS spreads, and positively in stressed periods, then leading to reduced spreads.

These are very relevant differences that should be taken into account when evaluating the risk of any credit portfolio. It would also be interesting to analyze in detail the relationship between GCRF and the main indicators of the real economy, like GDP or the unemployment rate. ${ }^{24}$

\footnotetext{
${ }^{24}$ See for example Contessi et al. (2013), who analyzed the relationship between loans and bonds and their connection with US GDP.
} 
We have also presented a short model to explain global credit risk using four factors of a different nature: equity, risk aversion, macroeconomic and financial factors. In the aftermath of the crisis, the equity, risk aversion and macroeconomic factors became important for the determination of GCRF, with market interest rates being of a lesser importance. The equity factor (MSCI indices) is the most relevant factor over most of the sample, with the macroeconomic factor (term structure and policy rates) and the financial factor (market interest rates) being particularly relevant for credit risk in 2011 and also between mid-2014 and mid-2015. The risk aversion factor was the most important factor in the aftermath of the financial crisis and became again relevant in the last part of the sample, after 2014.

An important application of our analysis is the use of the estimated GCRF for stress testing a credit portfolio. The factor model produces a drastic increase in expected CDS spreads, under a stress scenario, right at the beginning of the financial crisis, that persisted over some time. Furthermore, we indicate how our analysis could be extended to perform the stress testing of any credit portfolio. Application of the methodology to different stress episodes shows a good performance of the stress-testing methodology we propose, designed on the four-factor model for GCRF. It also shows the strong convenience of using for stress testing exercises as well as for the estimation of provisions and capital requirements factor sensitivities estimated from quantile regression models.

Finally, we have used a univariate sorting of individual CDSs into portfolios, as well as a Fama and MacBeth type of analysis to provide evidence suggesting that default-related risk is priced in the credit market. This is a central issue for risk supervisors, because lack of valuation by the market would create incentives to investors to undervalue risks, thereby assuming in their portfolios an excessive amount of risk that could produce instability in the global credit markets, as was the case before the financial crisis. We show that there is a significant market price for credit market and default-related risk factors in calm periods, which is not obtained in stressed periods. This result is robust to the addition of the 3-factor Fama-French risk factors to the model.

Our work contributes to the literature by describing how a global credit risk indicator that turns out to capture some information similar to that in existent indicators of financial stress can be easily estimated. Besides the applications of GCRF for risk management that we have just described, our analysis brings up relevant issues: the close correlation of GCRF with MSCI indices suggests that the equity market performs as a subordinated debt market in times of crisis, so that it could be thought of as a natural hedge for the debt market, with the advantage of being very liquid. Unfortunately, under the current regulation this hedge would be penalized, with a high increase in capital requirements. Whether or not this is an optimal regulation on the basis of our result is an interesting controversial open question.

Our analysis should be extended along two lines. Any financial institution would be interested in establishing the relationship between GCRF and the use of the committed undrawn credit lines in a 
credit stress scenario in which most of the borrowers will use these credit lines at the same time. ${ }^{25}$ Given the difficulty for a financial institution to estimate the credit conversion factor (CCF) of these undrawn credit lines for each borrower, the CCF is usually assumed to be constant at the level of $50 \%$ with independence of current economic circumstances. However, it would be more useful and risk sensitive to try to infer the CCF of a particular credit portfolio (small-medium enterprises portfolio, for instance) as a linear function of GCRF. We would expect that these undrawn credit lines might increase simultaneously if there were an increase in the level of global risk. This type of estimation would allow a bank to manage its risk more accurately, reflecting better the current economic environment and its potential adverse consequences.

Indeed, the new International Financial Reporting Standard, (IFRS 9) published by IASB (2014), requires banks from 2018 onwards to calculate the expected loss to provision each loan based on forward-looking information. It should be stressed that the historical default rates implied by credit ratings assigned by agencies such as Standard \& Poor's or Moody's are historical rates for corporate debt. Therefore, without any adjustment, they would not satisfy the IFRS 9 standards that require the calculation of expected losses based on current conditions and forecasts of future conditions, specified on the basis of reasonable and supportable information. To that respect, our GCRF and the characterization of the factors underlying its evolution over time can be central to estimating this expected loss as well as to designing a stress scenario, as we have shown. If we could infer the market premium risk between the historical probability of default and the risk neutral probability of default implied in GCRF, we could incorporate the forward-looking information in the rating estimated by the agencies and the internal models of the financial institutions.

\section{References}

Acharya, V., Drechsler, I., Schnabl, P., 2014. A pyrrhic victory? Bank bailouts and sovereign credit risk. The Journal of Finance 69 (6), 2689-2739.

Alexander, C., 2009. Market Risk Analysis, Value at Risk Models. Vol. 4. John Wiley \& Sons.

Ballester, L., Casu, B., González-Urteaga, A., 2016. Bank fragility and contagion: Evidence from the bank CDS market. Journal of Empirical Finance 38, 394-416.

BCBS, 2006. Basel II: International convergence of capital measurement and capital standards: A revised framework - comprehensive version. Basel Committee on Banking Supervision, Basel.

BCBS, 2011. Basel III: A global regulatory framework for more resilient banks and banking systems. Basel Committee on Banking Supervision, Basel.

Beirne, J., 2012. The EONIA spread before and during the crisis of 2007-2009: The role of liquidity and credit risk. Journal of International Money and Finance 31 (3), 534-551.

\footnotetext{
${ }^{25}$ See, for example, Ivashina and Scharfstein (2010)
} 
Berndt, A., Douglas, R., Duffie, D., Ferguson, M., Schranz, D., 2005. Measuring default risk premia from default swap rates and EDFs.

Berndt, A., Obreja, I., 2010. Decomposing European CDS returns. Review of Finance 14 (2), 189-233.

Blanco, R., Brennan, S., Marsh, I. W., 2005. An empirical analysis of the dynamic relationship between investment-grade bonds and credit default swaps. The Journal of Finance 63 (2), 2255-2281.

Blix Grimaldi, M., 2010. Detecting and interpreting financial stress in the euro area. Tech. rep., ECB working paper 1214.

BoJ, 2007. The framework for macro stress-testing of credit risk: Incorporating transition in borrower classifications. Box 8 in Financial System Report, September 2007, Bank of Japan.

Calice, G., 2014. CDX and iTraxx and their relation to the systemically important financial institutions: Evidence from the 2008-2009 financial crisis. Journal of International Financial Markets, Institutions and Money 32, 20-37.

Campa, J. M., Chang, P. K., 1998. The forecasting ability of correlations implied in foreign exchange options. Journal of International Money and Finance 17 (6), 855-880.

Campbell, J. Y., Taksler, G. B., 2003. Equity volatility and corporate bond yields. The Journal of Finance 58 (6), 2321-2350.

Castrén, O., Fitzpatrick, T., Sydow, M., 2009. Assessing portfolio credit risk changes in a sample of EU large and complex banking groups in reaction to macroeconomic shocks. ECB working paper 1002, February 2009 (1002).

Chen, C. Y.-H., Härdle, W. K., 2015. Common factors in credit defaults swap markets. Computational Statistics 30 (3), 845-863.

Chun, O. M., Dionne, G., François, P., 2014. Credit spread changes within switching regimes. Journal of Banking \& Finance 49, 41-55.

Claußen, A., Löhr, S., Rösch, D., Scheule, H., May 2017. Valuation of systematic risk in the cross-section of credit default swap spreads. The Quarterly Review of Economics and Finance. Published online, April 2016 64, 183-195.

Contessi, S., Li, L., Russ, K., et al., 2013. Bank vs. bond financing over the business cycle. Economic Synopses, Federal Reserve Bank of St. Louis, n.31, 2013.

Dempster, M. A. H., 2002. Risk management: value at risk and beyond. Cambridge University Press.

Díaz, A., Groba, J., Serrano, P., 2013. What drives corporate default risk premia? evidence from the CDS market. Journal of international money and finance 37, 529-563.

Driessen, J., 2004. Is default event risk priced in corporate bonds? The Review of Financial Studies 18 (1), 165-195.

Driessen, J., Maenhout, P. J., Vilkov, G., 2009. The price of correlation risk: Evidence from equity options. The Journal of Finance 64 (3), 1377-1406.

EBA, 2016. EU wide stress test methodological note. The European Banking Authority.

Eichengreen, B., Mody, A., Nedeljkovic, M., Sarno, L., 2012. How the subprime crisis went global: Evidence from bank credit default swap spreads. Journal of International Money and Finance 31 (5), 
1299-1318.

Ejsing, J., Lemke, W., 2011. The Janus-headed salvation: Sovereign and bank credit risk premia during 2008-2009. Economics Letters 110 (1), 28-31.

Ericsson, J., Jacobs, K., Oviedo, R., 2009. The determinants of credit default swap premia. Journal of Financial and Quantitative Analysis 44 (01), 109-132.

Fama, E. F., MacBeth, J. D., 1973. Risk, return, and equilibrium: Empirical tests. The Journal of Political Economy, 607-636.

Guesmi, K., Dhaoui, A., Goutte, S., Abid, I., 2018. On the determinants of industry-CDS index spreads: Evidence from a nonlinear setting. Journal of International Financial Markets, Institutions and Money 56, 233-254.

Hammoudeh, S., Nandha, M., Yuan, Y., 2013. Dynamics of CDS spread indexes of US financial sectors. Applied Economics 45 (2), 213-223.

Hui, C.-H., Lo, C.-F., Lau, C.-S., 2013. Option-implied correlation between iTraxx Europe Financials and Non-Financials indexes: A measure of spillover effect in european debt crisis. Journal of Banking \& Finance 37 (9), 3694-3703.

Iannotta, G., Pennacchi, G., 2012. Bank regulation, credit ratings, and systematic risk. SSRN (2021355). IASB, 2014. IFRS 9 financial instruments. International Accounting Standards Committee Foundation. Illing, M., Aaron, M., 2005. A brief survey of risk-appetite indexes. In: Bank of Canada Financial System Review.

Ivashina, V., Scharfstein, D., 2010. Bank lending during the financial crisis of 2008. Journal of Financial economics 97 (3), 319-338.

Jarrow, R. A., Lando, D., Yu, F., 2005. Default risk and diversification: Theory and empirical implications. Mathematical Finance: An International Journal of Mathematics, Statistics and Financial Economics 15 (1), 1-26.

Jiménez, G., Mencía, J., 2009. Modelling the distribution of credit losses with observable and latent factors. Journal of Empirical Finance 16 (2), 235-253.

Longstaff, F. A., Pan, J., Pedersen, L. H., Singleton, K. J., 2011. How sovereign is sovereign credit risk? American Economic Journal: Macroeconomics 3 (2), 75-103.

Longstaff, F. A., Schwartz, E. S., 1995. A simple approach to valuing risky fixed and floating rate debt. The Journal of Finance 50 (3), 789-819.

Lopez, J., Walter, C., 2000. Is implied correlation worth calculating? Evidence from foreign exchange options and historical data. Journal of Derivatives 7 (3), 65-81.

Markit, 2008. Markit.com user guide. Version 14.3.

Markit, 2012. Markit.com user guide CDS \& bonds. Version 16.

Novales, A., Chamizo, A., 2019. Splitting credit risk into systemic, sectorial and idiosyncratic components. Journal of Risk and Financial Management 12 (3), 129.

Ornelas, J. R. H., 2019. Expected currency returns and volatility risk premia. The North American Journal of Economics and Finance 49, 206-234. 
Pan, J., Singleton, K. J., 2008. Default and recovery implicit in the term structure of sovereign CDS spreads. The Journal of Finance 63 (5), 2345-2384.

Pereira, J., Sorwar, G., Nurullah, M., 2018. What drives corporate CDS spreads? A comparison across US, UK and EU firms. Journal of International Financial Markets, Institutions and Money 56, 188200.

Pires, P., Pereira, J. P., Martins, L. F., 2015. The empirical determinants of credit default swap spreads: A quantile regression approach. European Financial Management 21 (3), 556-589.

Puzanova, N., Düllmann, K., 2013. Systemic risk contributions: A credit portfolio approach. Journal of Banking \& Finance 37 (4), 1243-1257.

Rodríguez-Moreno, M., Peña, J. I., 2013. Systemic risk measures: The simpler the better? Journal of Banking \& Finance 37 (6), 1817-1831.

Schwaab, B., Koopman, S. J., Lucas, A., 2017. Global credit risk: World, country and industry factors. Journal of Applied Econometrics 32 (2), 296-317.

Siegel, A. F., 1997. International currency relationship information revealed by cross-option prices. The Journal of Futures Markets (1986-1998) 17 (4), 369.

Skintzi, V. D., Refenes, A.-P. N., 2005. Implied correlation index: A new measure of diversification. Journal of Futures Markets: Futures, Options, and Other Derivative Products 25 (2), 171-197.

S\&P, 2016. Transition, and recovery: 2015 annual global corporate default study and rating transitions. Report, Standard and Poors, May 2016.

Tang, D. Y., Yan, H., 2010. Market conditions, default risk and credit spreads. Journal of Banking \& Finance 34 (4), 743-753.

Tang, D. Y., Yan, H., 2013. What moves CDS spreads? SSRN (1786354).

Thornton, D. L., et al., 2009. What the LIBOR-OIS spread says. Economic Synopses, Federal Reserve Bank of Saint Louis, n.24, 2009.

Yu, F., 2002. Modeling expected return on defaultable bonds. The Journal of Fixed Income 12 (2), 69-81. Zhang, B. Y., Zhou, H., Zhu, H., 2009. Explaining credit default swap spreads with the equity volatility and jump risks of individual firms. Review of Financial Studies 22 (12), 5099-5131. 


\section{Appendix}

Table 1: Maximum likelihood estimates of default model for CD spreads

\begin{tabular}{|c|c|c|c|c|c|c|c|c|c|c|c|}
\hline & BM & CG & CS & EN & FIN & GOV & HC & IND & TEC & TEL & UTI \\
\hline \hline$k Q$ & 0.257 & 0.236 & 0.286 & 0.228 & 0.261 & 0.207 & 0.227 & 0.273 & 0.264 & 0.245 & 0.290 \\
\hline$k Q \theta Q$ & -0.677 & -0.689 & -0.773 & -0.607 & -0.791 & -0.687 & -0.665 & -0.778 & -0.737 & -0.734 & -0.972 \\
\hline$\sigma$ & 0.454 & 0.364 & 0.462 & 0.429 & 0.438 & 0.503 & 0.389 & 0.463 & 0.446 & 0.647 & 0.425 \\
\hline$k P$ & 0.264 & 0.014 & 0.076 & 0.000 & 0.117 & 0.214 & 0.007 & 0.119 & 0.129 & 0.149 & 0.024 \\
\hline$k P \theta P$ & -1.543 & -0.168 & -0.453 & -0.001 & -0.738 & -1.034 & -0.048 & -0.735 & -0.693 & -0.485 & -0.076 \\
\hline$\sigma_{1}$ (bps) & 15.80 & 10.79 & 10.94 & 16.67 & 17.16 & 17.46 & 10.00 & 12.10 & 12.99 & 17.25 & 14.63 \\
\hline$\sigma_{3}$ (bps) & 6.88 & 6.67 & 8.04 & 8.83 & 9.23 & 13.60 & 6.37 & 7.07 & 9.14 & 8.28 & 7.69 \\
\hline$\sigma_{7}$ (bps) & 7.13 & 6.67 & 8.04 & 8.65 & 9.23 & 13.67 & 6.37 & 7.14 & 9.14 & 8.28 & 7.68 \\
\hline$\sigma_{10}$ (bps) & 6.99 & 6.67 & 8.04 & 8.85 & 9.23 & 13.57 & 6.37 & 7.07 & 9.14 & 8.28 & 7.65 \\
\hline & & & & & & & & & & & \\
\hline delta0 & -1.907 & 1.435 & 0.693 & 1.410 & 0.122 & -0.690 & 1.586 & 0.093 & 0.099 & 0.384 & 2.106 \\
\hline delta1 & -0.016 & 0.610 & 0.454 & 0.531 & 0.329 & -0.016 & 0.563 & 0.331 & 0.302 & 0.147 & 0.626 \\
\hline & & & & & & & & & & & \\
\hline$\theta Q$ & 0.072 & 0.054 & 0.067 & 0.070 & 0.048 & 0.036 & 0.053 & 0.058 & 0.061 & 0.050 & 0.035 \\
\hline$\theta P$ & 0.003 & 0.000 & 0.003 & 0.049 & 0.002 & 0.008 & 0.002 & 0.002 & 0.005 & 0.039 & 0.039 \\
\hline logLik & 14996.6 & 15762.2 & 14901.6 & 14660.5 & 14392.5 & 13856.8 & 15617.2 & 15183.7 & 14611.6 & 14437.5 & 15195.4 \\
\hline
\end{tabular}

Note: The table shows maximum likelihood estimates for the parameters of the stochastic processes described in section 4 to model the default-related component of observed CDS spreads. The last row shows the maximized log-likelihood values. 
Table 2: Default risk premium

\begin{tabular}{|c|c|c|c|c|c|}
\hline & 1 year & 3 year & 5 year & 7 year & 10 year \\
\hline \hline \multicolumn{5}{|c|}{ panel a: Default risk premium } \\
\hline BM & 13.1 & 49.4 & 92.1 & 132.2 & 179.3 \\
\hline CG & 10.0 & 35.5 & 64.5 & 91.9 & 124.9 \\
\hline CS & 14.2 & 53.2 & 96.7 & 135.4 & 178.7 \\
\hline EN & 10.0 & 37.7 & 69.7 & 101.3 & 139.3 \\
\hline FIN & 17.0 & 53.4 & 87.6 & 115.4 & 145.5 \\
\hline GOV & 7.6 & 26.0 & 45.0 & 62.0 & 81.8 \\
\hline HC & 7.2 & 27.1 & 51.5 & 75.9 & 106.3 \\
\hline IND & 13.3 & 47.9 & 85.9 & 120.0 & 157.6 \\
\hline TEC & 12.4 & 45.4 & 82.0 & 115.2 & 152.4 \\
\hline TEL & 10.8 & 41.9 & 77.8 & 111.8 & 152.5 \\
\hline UTI & 8.0 & 27.5 & 46.4 & 62.1 & 76.5 \\
\hline Median & $\mathbf{1 0 . 8}$ & $\mathbf{4 1 . 9}$ & $\mathbf{7 7 . 8}$ & $\mathbf{1 1 1 . 8}$ & $\mathbf{1 4 5 . 5}$ \\
\hline \multicolumn{6}{|c|}{ panel b: Default risk premium / market CDS } \\
\hline BM & $33 \%$ & $66 \%$ & $79 \%$ & $84 \%$ & $88 \%$ \\
\hline CG & $28 \%$ & $59 \%$ & $73 \%$ & $80 \%$ & $85 \%$ \\
\hline CS & $31 \%$ & $62 \%$ & $74 \%$ & $80 \%$ & $84 \%$ \\
\hline EN & $26 \%$ & $54 \%$ & $67 \%$ & $73 \%$ & $77 \%$ \\
\hline FIN & $26 \%$ & $54 \%$ & $68 \%$ & $75 \%$ & $80 \%$ \\
\hline GOV & $86 \%$ & $66 \%$ & $55 \%$ & $47 \%$ & $41 \%$ \\
\hline HC & $27 \%$ & $56 \%$ & $70 \%$ & $76 \%$ & $80 \%$ \\
\hline IND & $31 \%$ & $62 \%$ & $75 \%$ & $81 \%$ & $85 \%$ \\
\hline TEC & $27 \%$ & $56 \%$ & $69 \%$ & $75 \%$ & $80 \%$ \\
\hline TEL & $27 \%$ & $58 \%$ & $72 \%$ & $79 \%$ & $83 \%$ \\
\hline UTI & $23 \%$ & $47 \%$ & $57 \%$ & $62 \%$ & $63 \%$ \\
\hline Median & $\mathbf{2 7 \%}$ & $\mathbf{5 8 \%}$ & $\mathbf{7 0 \%}$ & $\mathbf{7 6 \%}$ & $\mathbf{8 0 \%}$ \\
\hline
\end{tabular}

Note: Panel a) shows median levels for the the estimated default-related component of CDS spreads across sectors at the different tenors. Panel b) shows the median of the default-related components of CDS spreads as a percentage of market spreads. 
Table 3: Basic statistics for sectorial default-related CDS spread indices

\begin{tabular}{|c|c|c|c|c|c|c|c|c|c|c|c|c|}
\hline & BM & CG & CS & EN & FIN & GOV & $\mathrm{HC}$ & IND & TEC & TEL & UTI & GCRF \\
\hline Median & 25.6 & 24.3 & 32.6 & 35.4 & 43.2 & 52.0 & 22.8 & 29.0 & 35.9 & 78.0 & 36.3 & 43.2 \\
\hline Maximum & 130.9 & 172.0 & 214.2 & 265.4 & 235.8 & 210.5 & 101.4 & 150.1 & 117.4 & 266.4 & 109.0 & 181.1 \\
\hline minimum & 5.0 & 3.1 & 5.0 & 2.0 & 0.6 & 6.9 & 5.3 & 2.8 & 10.9 & 26.5 & 1.0 & 8.1 \\
\hline Standard deviation & 19.9 & 25.8 & 36.9 & 46.2 & 41.6 & 35.9 & 17.8 & 27.3 & 20.6 & 42.4 & 26.0 & 32.9 \\
\hline Range & 125.9 & 168.8 & 209.2 & 263.4 & 235.2 & 203.6 & 96.1 & 147.3 & 106.5 & 239.9 & 108.0 & 173.0 \\
\hline Skewness & 2.3 & 2.7 & 2.6 & 2.7 & 1.6 & 1.2 & 2.0 & 2.0 & 1.1 & 1.4 & 0.6 & 1.8 \\
\hline Kurtosis & 10.5 & 11.8 & 10.5 & 11.2 & 6.2 & 5.9 & 8.1 & 8.0 & 4.3 & 6.1 & 3.0 & 7.6 \\
\hline Jarque-Bera & 1664 & 2308 & 1818 & 2082 & 434 & 312 & 912 & 880 & 143 & 371 & 31 & 751 \\
\hline \multicolumn{13}{|c|}{ Unit root tests: Default-related spread indices } \\
\hline & BM & CG & CS & EN & FIN & GOV & $\mathrm{HC}$ & IND & TEC & TEL & UTI & GCRF \\
\hline adf1 & -1.17 & -1.52 & -1.29 & -1.24 & -1.27 & -0.88 & -1.33 & -1.22 & -0.99 & -0.85 & -0.78 & -0.76 \\
\hline adf4 & -1.24 & -1.75 & -1.50 & -1.29 & -1.47 & -0.92 & -1.41 & -1.38 & -1.00 & -0.78 & -1.06 & -1.11 \\
\hline adf8 & -1.27 & -1.42 & -1.49 & -1.81 & -1.49 & -1.14 & -1.41 & -1.63 & -0.93 & -1.03 & -1.05 & -1.29 \\
\hline & \multicolumn{11}{|c|}{ Unit root tests: Weekly changes in default-related spread indices } & \\
\hline adf1 & -11.1 & -12.5 & -12.0 & -13.4 & -12.5 & -12.4 & -17.5 & -12.7 & -15.1 & -15.9 & -12.7 & 12.7 \\
\hline adf4 & -9.2 & -9.3 & -8.6 & -7.1 & -9.54 & -8.7 & -8.2 & -7.8 & -9.7 & -10.5 & -8.2 & -8.5 \\
\hline adf8 & -6.9 & -7.7 & -6.5 & -4.8 & -7.2 & -6.4 & -6.2 & -6.31 & -6.9 & -6.7 & -6.4 & -6.1 \\
\hline
\end{tabular}

Note: The table shows the main statistics for sectorial default-related CDS spread indices, which were constructed as describe in the paper. BM $=$ Basic materials, $\mathrm{CG}=$ Consumer goods, $\mathrm{CS}=$ Consumer services, $\mathrm{EN}=$ Energy, FIN = Financials, GOV = Government, $\mathrm{HC}=\mathrm{Healthcare}, \mathrm{IND}=$ Industrials, TEC $=$ Technology, TEL = Telecommunication services, and UTI = Utilities. adf1, adf4, adf8 are the values of the Augmented DickeyFuller statistic including a constant 1, 4 and 8 lags for either CDS spreads in levels (upper panel) or weekly percent changes (lower panel). Critical values at $[1 \% 5 \% 10 \%]$ probability are: $-3.4583-2.8710-2.5937$

Table 4: Relevance of systemic and idiosyncratic components

\begin{tabular}{|c|c|c|c|c|}
\hline & Correlation & R-squared (full sample) & median R-squared & 1-median(R-squared) \\
\hline \hline BM & 0.789 & 0.622 & 0.572 & 0.427 \\
\hline CG & 0.820 & 0.672 & 0.649 & 0.351 \\
\hline CS & 0.898 & 0.806 & 0.616 & 0.383 \\
\hline EN & 0.861 & 0.741 & 0.726 & 0.274 \\
\hline FIN & 0.869 & 0.755 & 0.784 & 0.216 \\
\hline GOV & 0.744 & 0.553 & 0.545 & 0.455 \\
\hline HC & 0.676 & 0.457 & 0.208 & 0.792 \\
\hline IND & 0.856 & 0.733 & 0.676 & 0.323 \\
\hline TEC & 0.657 & 0.432 & 0.387 & 0.613 \\
\hline TEL & 0.851 & 0.723 & 0.777 & 0.223 \\
\hline UTI & 0.778 & 0.606 & 0.607 & 0.393 \\
\hline
\end{tabular}

Note: The second column of the table shows the correlation coefficient between the default-related CDS spread indices and the GCRF. Column 3 is the R-squared from regressions of the default-related CDS spread indices on GCRF. Column 4 is the sample median of the R-squared from those regressions, while column 5 is the sample median of one minus those R-squared statistics. 
Table 5: GCRF regressions

\begin{tabular}{|c|c|c|c|c|}
\hline & \multicolumn{3}{|c|}{ GCRF } & Corporate GCRF \\
\hline constant & $-0.12(-0.9)$ & $0.02(0.2)$ & $-0.08(0.6)$ & $-0.08(0.6)$ \\
\hline VIX & $0.36(5.9)$ & & & \\
\hline VCDX & $6.84(2.0)$ & & & \\
\hline ivswapUS & $0.10(3.7)$ & & $0.07(472)$ & $0.07(3.0)$ \\
\hline libor_ovn & $-17.05(5.0)$ & & $-14.76(4.7)$ & $-16.07(7.3)$ \\
\hline euro_dollar & $-25.94(2.7)$ & & & \\
\hline eonia & $-12.55(3.8)$ & & $-7.72(2.5)$ & $-5.74(1.8)$ \\
\hline yswap1 & $36.33(3.3)$ & & $36.85(3.7)$ & $25.33(3.3)$ \\
\hline yswap5 & $-19.65(3.4)$ & & $-9.03(1.72)$ & \\
\hline USslope & $-16.48(8.0)$ & & $-15.31(8.0)$ & $-14.01(8.6)$ \\
\hline UScurv & $-4.48(1.8)$ & & $-4.24(1.9)$ & \\
\hline eucurv & $-9.41(3.1)$ & & $-8.72(3.2)$ & $-9.47(2.4)$ \\
\hline MSCI Basic materials & & $-0.13(4.2)$ & $-0.06(2.2)$ & $-0.07(2.4)$ \\
\hline MSCI Financials & & $-0.73(8.9)$ & $-0.63(7.9)$ & $-0.63(7.6)$ \\
\hline adjusted R2 & 0.452 & 0.412 & 0.532 & 0.505 \\
\hline
\end{tabular}

Note: The first three regressions have GCRF as dependent variable. The dependent variable in the last regression is the estimate of GCRF obtained excluding government and financial sectors. Estimates have been obtained with the full sample of 521 weekly observations. Explanatory variables are: ivswapUS: the implied volatility in 5-year US swaption rates; libor_ovn: USD liquidity premium, measured by the absolute difference between three-month LIBOR and the three-month OIS Index; eonia: the EONIA rate; yswap1 and yswap5: 1- and 5-year yen swap rates; USslope: US term structure slope, defined as the 10-year, 1-year rates spread, $r_{t, 10}-r_{t, 1}$, in swap rates in US dollars; UScurv and eucurv: US and euro term structure curvatures, defined as $r_{t, 10}-2 r_{t, 5}+r_{t, 1}$, from swap rates in US dollars and euros, respectively.

Table 6: Regression models on standardized synthetic indicators

\begin{tabular}{|c|c|c|c|c|c|c|}
\hline & GCRF & BM & CG & CS & EN & FIN \\
\hline \hline constant & $0.08(0.5)$ & $0.17(1.1)$ & $0.11(0.8)$ & $0.13(0.9)$ & $0.31(2.0)$ & $0.30(2.0)$ \\
\hline MSCI & $-1.61(9.8)$ & $-1.35(7.2)$ & $-1.22(7.4)$ & $-1.41(8.2)$ & $-1.68(9.1)$ & $-1.57(8.5)$ \\
\hline Risk & $0.96(6.1)$ & $1.04(5.8)$ & $0.96(6.0)$ & $0.81(4.9)$ & $1.07(6.1)$ & $1.43(8.1)$ \\
\hline Macro & $-1.91(3.3)$ & $-0.15(0.4)$ & $-0.68(2.2)$ & $-0.39(1.2)$ & $-0.47(1.4)$ & $-1.46(4.2)$ \\
\hline Financial & $-0.01(0.1)$ & $-0.78(2.2)$ & $-0.44(1.4)$ & $-0.56(1.7)$ & $-0.45(1.3)$ & $0.13(0.4)$ \\
\hline adjustedR2 & 0.40 & 0.29 & 0.33 & 0.31 & 0.35 & 0.42 \\
\hline & GOV & HC & IND & TEC & TEL & UTI \\
\hline \hline constant & $0.29(1.4)$ & $0.09(0.5)$ & $0.14(1.0)$ & $-0.00(0.0)$ & $0.18(1.0)$ & $0.17(1.3)$ \\
\hline MSCI & $-1.76(7.1)$ & $-0.81(4.1)$ & $-1.37(7.8)$ & $-0.89(4.5)$ & $-2.19(10.2)$ & $-0.94(6.1)$ \\
\hline Risk & $1.20(5.1)$ & $0.59(3.1)$ & $0.86(5.1)$ & $1.08(5.8)$ & $0.98(4.8)$ & $1.03(7.0)$ \\
\hline Macro & $-0.81(1.7)$ & $-0.45(1.2)$ & $-0.64(1.9)$ & $-0.04(0.1)$ & $-0.93(2.3)$ & $-0.59(2.1)$ \\
\hline Financial & $-0.29(0.6)$ & $-0.26(0.7)$ & $-0.51(1.5)$ & $-0.87(2.4)$ & $0.30(0.7)$ & $-0.29(1.0)$ \\
\hline adjustedR2 & 0.27 & 0.12 & 0.33 & 0.20 & 0.38 & 0.30 \\
\hline
\end{tabular}

Note: Estimated coefficients in synthetic factor regressions. The second column has GCRF as dependent variable. The remaining regressions have a sectorial index as dependent variable. $\mathrm{BM}=$ Basic materials, $\mathrm{CG}=$ Consumer goods, $\mathrm{CS}=$ Consumer services, $\mathrm{EN}=\mathrm{Energy}, \mathrm{FIN}=\mathrm{Financials}$, GOV $=$ Government, $\mathrm{HC}=$ Healthcare, $\mathrm{IND}=$ Industrials, $\mathrm{TEC}=$ Technology, $\mathrm{TEL}=$ Telecommunication services, and UTI $=$ Utilities 
Table 7: Quantile regression estimates for GCRF

\begin{tabular}{|c|c|c|c|c|c|}
\hline & constant & MSCI & Risk & Macro & Financial \\
\hline \hline $10 \%$ & -2.62 & -1.47 & 0.31 & -2.51 & 1.83 \\
\hline $20 \%$ & -1.24 & -1.19 & 0.68 & -1.26 & 0.73 \\
\hline $30 \%$ & -0.63 & -1.01 & 0.63 & -1.12 & 0.68 \\
\hline $40 \%$ & -0.27 & -1.02 & 0.63 & -1.11 & 0.62 \\
\hline $50 \%$ & 0.00 & -0.97 & 0.60 & -1.19 & 0.64 \\
\hline $60 \%$ & 0.32 & -1.18 & 0.51 & -0.80 & 0.28 \\
\hline $70 \%$ & 0.72 & -1.28 & 0.54 & -0.87 & 0.36 \\
\hline $80 \%$ & 1.42 & -1.53 & 0.62 & -0.16 & -0.53 \\
\hline $90 \%$ & 2.93 & -1.75 & 1.10 & 0.31 & -1.57 \\
\hline F(1,1041) & & 2.27 & 0.09 & 3.94 & 4.92 \\
\hline p-value & & 0.13 & 0.76 & 0.04 & 0.03 \\
\hline
\end{tabular}

Note: The rows in the table display estimated coefficients in quantile regressions for quantiles from $\mathrm{q}=0.10$ to $\mathrm{q}=0.90$. The last two rows show the value of the F-statistic and its $\mathrm{p}$-value, for the test of equality of each estimated coefficient in quantile regressions for quantiles: $\mathrm{q}=0.20$ and $\mathrm{q}=0.80$. Degrees of freedom are 1 and 1037 for each test. The joint test of equality for all the coefficients for quantiles: $\mathrm{q}=0.20$ and $\mathrm{q}=0.80$ has a test statistic of 2.22 with degrees of freedom $(4 ; 1038)$ and p-value of 0.06

Table 8: Stress testing outcome

\begin{tabular}{|c|c|c|c|c|c|c|}
\hline & $\begin{array}{c}\text { Highest } \\
\text { change }\end{array}$ & $\begin{array}{c}\text { Standard } \\
\text { deviation }\end{array}$ & $\begin{array}{c}\text { Stressed } \\
\text { effect }\end{array}$ & Stress/Highest & Stress/Std.Dev. & $\begin{array}{c}\text { Estimate through } \\
\text { GCRF-beta }\end{array}$ \\
\hline \hline GCRF & 32.1 & 4.00 & 22.7 & 0.71 & 5.7 & \\
\hline Basic materials & 21.8 & 2.69 & 11.3 & 0.52 & 4.2 & 14.1 \\
\hline Consumer goods & 25.0 & 3.54 & 15.7 & 0.63 & 4.4 & 15.3 \\
\hline Consumer services & 37.6 & 4.63 & 24.5 & 0.65 & 5.3 & 18.3 \\
\hline Energy & 47.9 & 6.25 & 27.9 & 0.58 & 4.5 & 16.8 \\
\hline Financials & 33.2 & 5.12 & 30.8 & 0.93 & 6.0 & 17.1 \\
\hline Government & 25.9 & 4.20 & 18.8 & 0.73 & 4.5 & 12.6 \\
\hline Healthcare & 27.7 & 2.88 & 11.4 & 0.41 & 3.9 & 10.4 \\
\hline Industrials & 16.1 & 3.16 & 14.1 & 0.88 & 4.5 & 16.6 \\
\hline Technology & 18.9 & 3.16 & 14.3 & 0.76 & 4.5 & 9.8 \\
\hline Telecommunication services & 58.2 & 7.48 & 39.3 & 0.68 & 5.3 & 16.4 \\
\hline Utilities & 15.2 & 3.01 & 14.5 & 0.96 & 4.8 & 13.8 \\
\hline
\end{tabular}

Note: The first and second columns in the table show the maximum weekly change in each index and its sample standard deviation, respectively. The third column displays the effect of stressing each synthetic factor by six standard deviations. The synthetic factors were orthogonalized for this exercise. The next two columns show the stressed effect as a multiple of the standard deviation and the sample maximum, respectively. The last column shows the stress test effect estimated using the effect on GCRF and the beta of each sectorial index with respect to GCRF. 
Table 9: Observed and estimated increase in spreads from the four-factor model

\begin{tabular}{|c|c|c|c|c|c|c|c|c|c|c|c|c|c|}
\hline \multicolumn{10}{|c|}{ Panel a: Observed changes in spreads } \\
\hline \hline GCRF & BM & CG & CS & EN & FIN & GOV & HC & IND & TEC & TEL & UTI & Median & Time period \\
\hline 17 & 14 & 13 & 31 & 15 & 18 & 13 & 10 & 13 & 23 & 19 & 11 & 14 & Sub-prime \\
\hline 174 & 188 & 129 & 184 & 234 & 217 & 201 & 81 & 193 & 122 & 132 & 95 & 184 & Lehman \\
\hline-171 & -181 & -122 & -215 & -236 & -195 & -172 & -88 & -172 & -125 & -155 & -85 & -172 & Stimulus Act \\
\hline 14 & 5 & -2 & 9 & 18 & 28 & 28 & 15 & 5 & 10 & 13 & 12 & 12 & Eurozone \\
\hline 1 & 1 & 6 & 6 & 8 & -2 & -14 & 2 & 1 & -6 & 5 & 13 & 2 & EU measures \\
\hline 31 & 52 & 18 & 15 & 39 & 40 & 22 & 9 & 29 & 40 & 39 & 24 & 29 & US rating downgrade \\
\hline-31 & -26 & -22 & -20 & -36 & -59 & -40 & -13 & -33 & -10 & -30 & -31 & -29 & Draghi \\
\hline \multicolumn{10}{|c|}{} \\
\hline GCRF & BM & CG & CS & EN & FIN & GOV & HC & IND & TEC & TEL & UTI & Median & Time period \\
\hline 6.3 & 1.5 & 3.1 & 16.1 & 3.1 & 3.6 & 6.1 & 3.6 & 2.8 & 4.0 & 15.1 & 2.9 & 3.6 & Subprime \\
\hline 75.1 & 35.7 & 56.9 & 85.5 & 101.0 & 84.8 & 52.4 & 40.9 & 44.9 & 47.3 & 115.9 & 44.0 & 52.4 & Lehman \\
\hline-51.5 & -39.5 & -53.8 & -54.9 & -75.6 & -68.7 & -54.9 & -24.5 & -41.0 & -29.3 & -48.7 & -17.8 & -48.7 & Stimulus Act \\
\hline 18.9 & 9.8 & 13.3 & 13.8 & 16.3 & 26.0 & 24.1 & 6.8 & 16.5 & 14.0 & 35.0 & 14.1 & 14.1 & Eurozone \\
\hline 9.3 & 3.9 & 4.2 & 10.8 & 5.1 & 15.5 & 15.6 & 4.0 & 10.88 & 3.7 & 22.8 & 5.7 & 5.7 & EU measures \\
\hline 30.0 & 16.8 & 15.8 & 22.3 & 25.3 & 35.8 & 31.3 & 13.6 & 21.3 & 22.2 & 56.0 & 37.4 & 22.4 & US rating downgrade \\
\hline-14.4 & -9.7 & -7.6 & -12.0 & -18.4 & -18.0 & -16.4 & -4.4 & -10.3 & -18.0 & -31.7 & -14.4 & -14.4 & Draghi \\
\hline
\end{tabular}

Note: Panel a) in the table shows the observed changes in CDS spreads over seven time periods of stress, in basis points. Panel b) shows the estimated changes in CDS spreads from the synthetic factor model over the seven time periods of stress. The composition of the synthetic factors and the description of the seven time periods of stress are explained in the paper.

Table 10: Performance of GCRF-beta portfolios

\begin{tabular}{|c|c|c|c|c|c|c|c|c|}
\hline & \multicolumn{7}{|c|}{ Portfolios } \\
\hline \hline & P1 & P2 & P3 & P4 & P5 & P6 & P7 & P8 \\
\hline Mean \% weekly spread change & 0.28 & 0.15 & 0.16 & 0.22 & 0.29 & 0.25 & 0.35 & 0.51 \\
\hline Annual \% spread change & $15.6 \%$ & $8.3 \%$ & $8.8 \%$ & $12.0 \%$ & $16.5 \%$ & $14.0 \%$ & $19.8 \%$ & $30.5 \%$ \\
\hline Average beta & -0.033 & 0.100 & 0.171 & 0.230 & 0.293 & 0.370 & 0.472 & 0.653 \\
\hline
\end{tabular}

Note: The table shows the mean spread change and its annual equivalent for eight equally weighted portfolios constructed after ranking CDS contracts according to their orthogonalized GCRF-beta. The first row is multiplied by 100. The orthogonalized GCRF is the residual of a linear regression of the GCRF on the market index. Portfolios were updated at the end of each month as a function of the GCRF betas estimated with daily observations for that month. The first portfolio (P1) contains firms with the lowest GCRF beta while the last portfolio (P8) is made up by firms with the highest GCRF beta. 
Table 11: The market price of risk

\begin{tabular}{|c|c|c|c|c|c|c|c|}
\hline & & $\lambda_{0}$ & $\lambda_{m}$ & $\lambda_{G R F}$ & $\lambda_{m k t-R f}$ & $\lambda_{S M B}$ & $\lambda_{H M L}$ \\
\hline \multicolumn{8}{|c|}{ Panel a } \\
\hline \multirow{2}{*}{ Single regime } & & -0.0005 & 0.0054 & & & & \\
\hline & & $(0.0056)$ & $(0.0035)$ & & & & \\
\hline \multirow{4}{*}{ Two regimes } & Jow volatility & -0.0045 & 0.0152 & & & & \\
\hline & LOW Voidtimty & $(0.0011)$ & $(0.0043)$ & & & & \\
\hline & & 0.0029 & -0.0024 & & & & \\
\hline & High volatility & $(0.0028)$ & $(0.0051)$ & & & & \\
\hline \multicolumn{8}{|c|}{ Panel b } \\
\hline \multirow{2}{*}{ Single regime } & & -0.0016 & -0.0004 & -0.0261 & & & \\
\hline & & $(.0015)$ & $(0.0056)$ & $(0.3345)$ & & & \\
\hline \multirow{4}{*}{ Two regimes } & Low volatility & -0.0024 & 0.0137 & -0.6010 & & & \\
\hline & Low voratimy & $(0.0012)$ & $(0.0073)$ & $(0.2450)$ & & & \\
\hline & High volatility & -0.0009 & -0.0121 & 0.4560 & & & \\
\hline & Hign voratimty & $(0.0026)$ & $(0.0083)$ & $(0.5786)$ & & & \\
\hline \multicolumn{8}{|c|}{ Panel c } \\
\hline \multicolumn{8}{|c|}{ Excluding Financials and Government } \\
\hline \multirow{2}{*}{ Single regime } & & -0.0007 & 0.0001 & -0.1833 & & & \\
\hline & & $(0.0017)$ & $(0.0058)$ & $(0.3168)$ & & & \\
\hline \multirow{4}{*}{ Two regimes } & Low volatility & -0.0012 & 0.0148 & -0.5787 & & & \\
\hline & & $(0.0012)$ & $(0.0074)$ & $(0.2334)$ & & & \\
\hline & High volatility & -0.0002 & -0.0121 & 0.1454 & & & \\
\hline & Hign voratilty & $(0.0029)$ & $(0.0085)$ & $(0.5465)$ & & & \\
\hline \multicolumn{8}{|c|}{ Panel d } \\
\hline \multirow{2}{*}{ Single regime } & & -0.0037 & -0.0011 & -0.0663 & -0.0365 & -0.0129 & 0.0070 \\
\hline & & $(0.0012)$ & $(0.0047)$ & $(0.2827)$ & $(0.0411)$ & $(0.0152)$ & $(0.0148)$ \\
\hline \multirow{4}{*}{ Two regimes } & & -0.0032 & 0.0106 & -0.3940 & -0.0718 & -0.0214 & 0.0069 \\
\hline & Low volatility & $(0.0009)$ & $(0.0062)$ & $(0.1985)$ & $(0.0487)$ & $(0.0187)$ & $(0.0158)$ \\
\hline & High volatility & -0.0041 & -0.0110 & -0.2084 & -0.0069 & -0.0057 & 0.0071 \\
\hline & 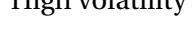 & $(0.0020)$ & $(0.0068)$ & $(0.4922)$ & $(0.0637)$ & $(0.0232)$ & $(0.0237)$ \\
\hline
\end{tabular}

Note: Estimates of market price of beta risk. Panel a) shows results using the credit market risk factor alone. Panel b) uses the credit market risk factor together with our GCRF estimate. Panel c) repeats the exercise in b) excluding the financial and government sectors. Panel d) adds the three Fama-French risk factors: Equity market, Small minus Big, and High minus Low. In each panel, we present results for the whole sample as well as for two sub-samples, defined by periods with a volatility of the innovation in weekly changes of the market index above or below its median. 
Figure 1: 5-year market CDS sectorial spread indices

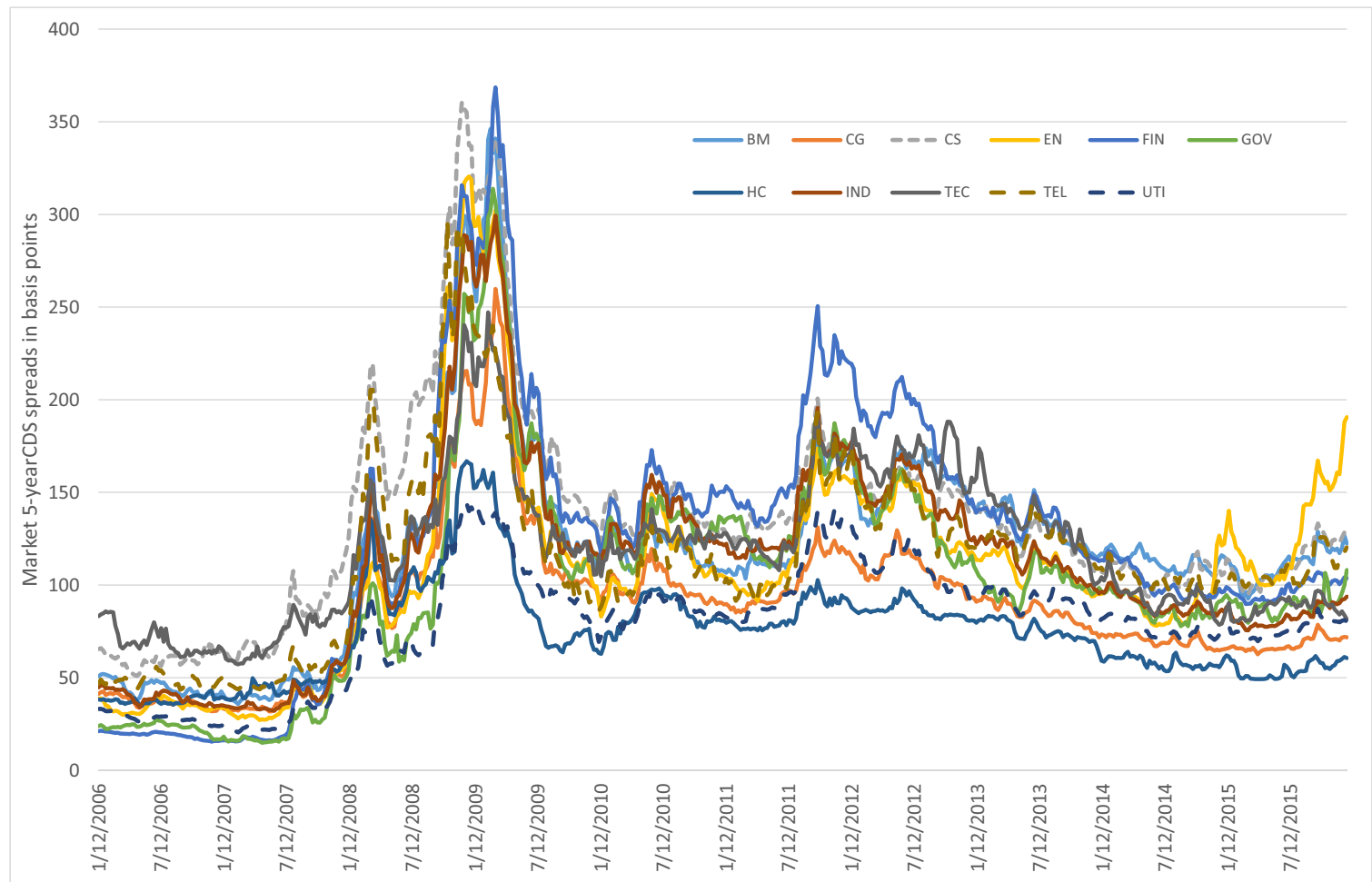

Note: The Figure shows CDS 5-year market CDS spread indices for the 11 sectors considered in the paper. The sectorial data was constructed as the median of CDS spreads traded by firms in a given sector in all regions with a 5 -year tenor. We estimated a time series of spreads for each sector and tenor.

Figure 2: Default-related components of 5-year market CDS sectorial spread indices

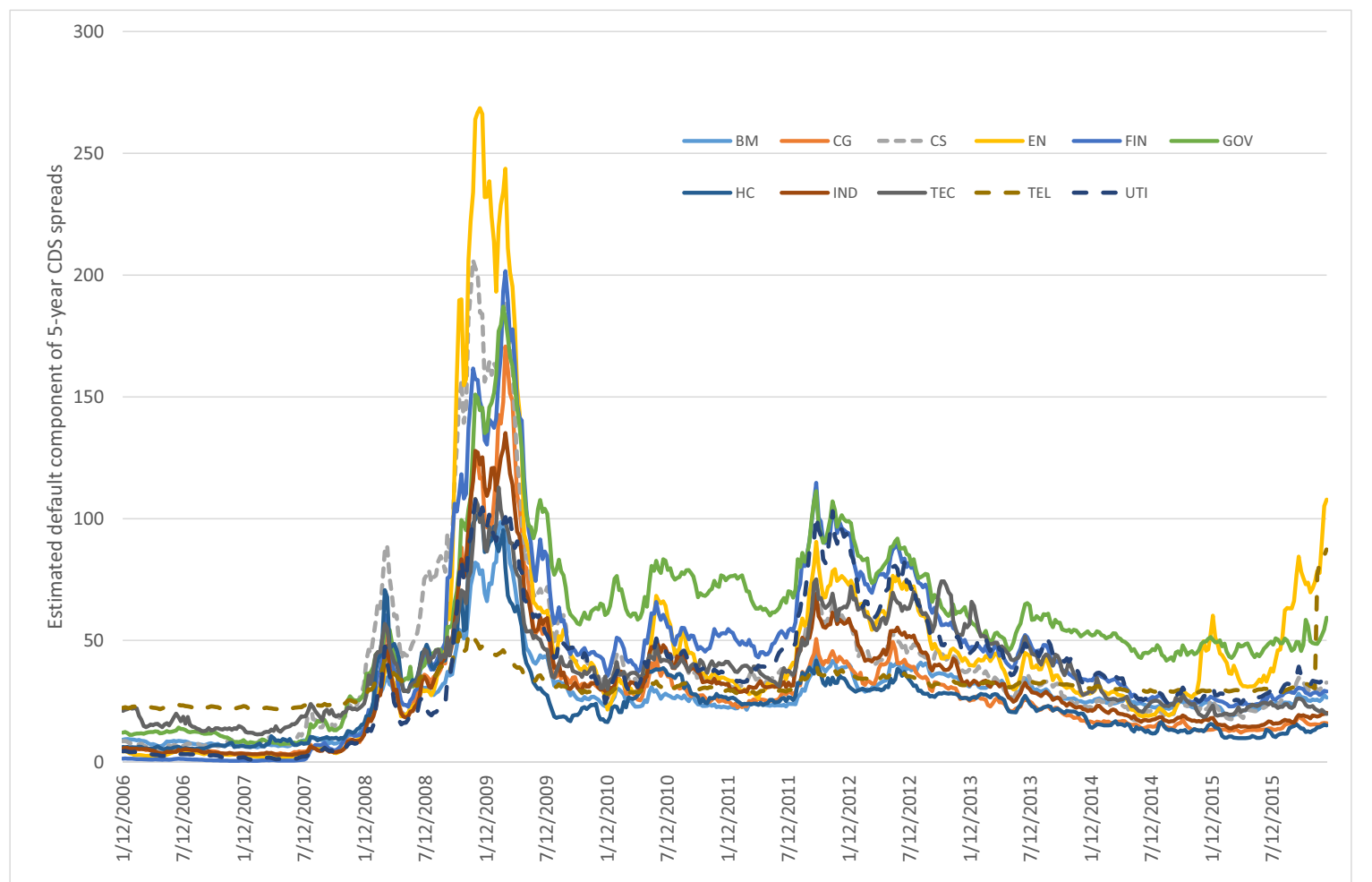

Note: The Figure shows the default-related component of 5-year market CDS spread indices. Such a component was estimated by application of the methodology described in Section 4 to the sectorial data shown in Figure. 
Figure 3: 5-year CDS default risk premium

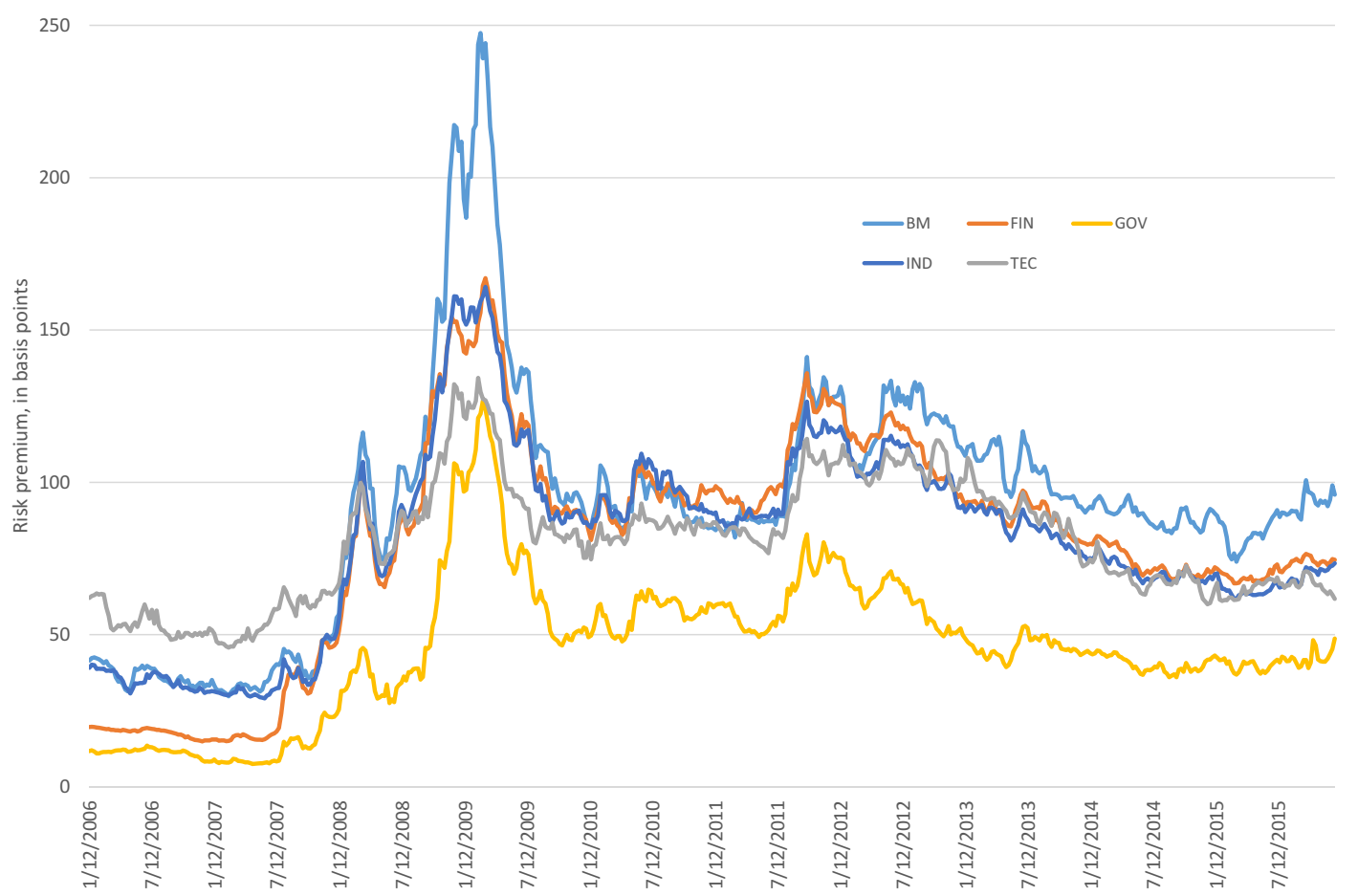

Note: The Figure shows the time evolution of estimates of the risk premium component of 5-year CDS spreads as a percentage of the theoretical spread for some selected sectors.

Figure 4: Relevance of the 10-year risk premium as a percentage of the theoretical spread

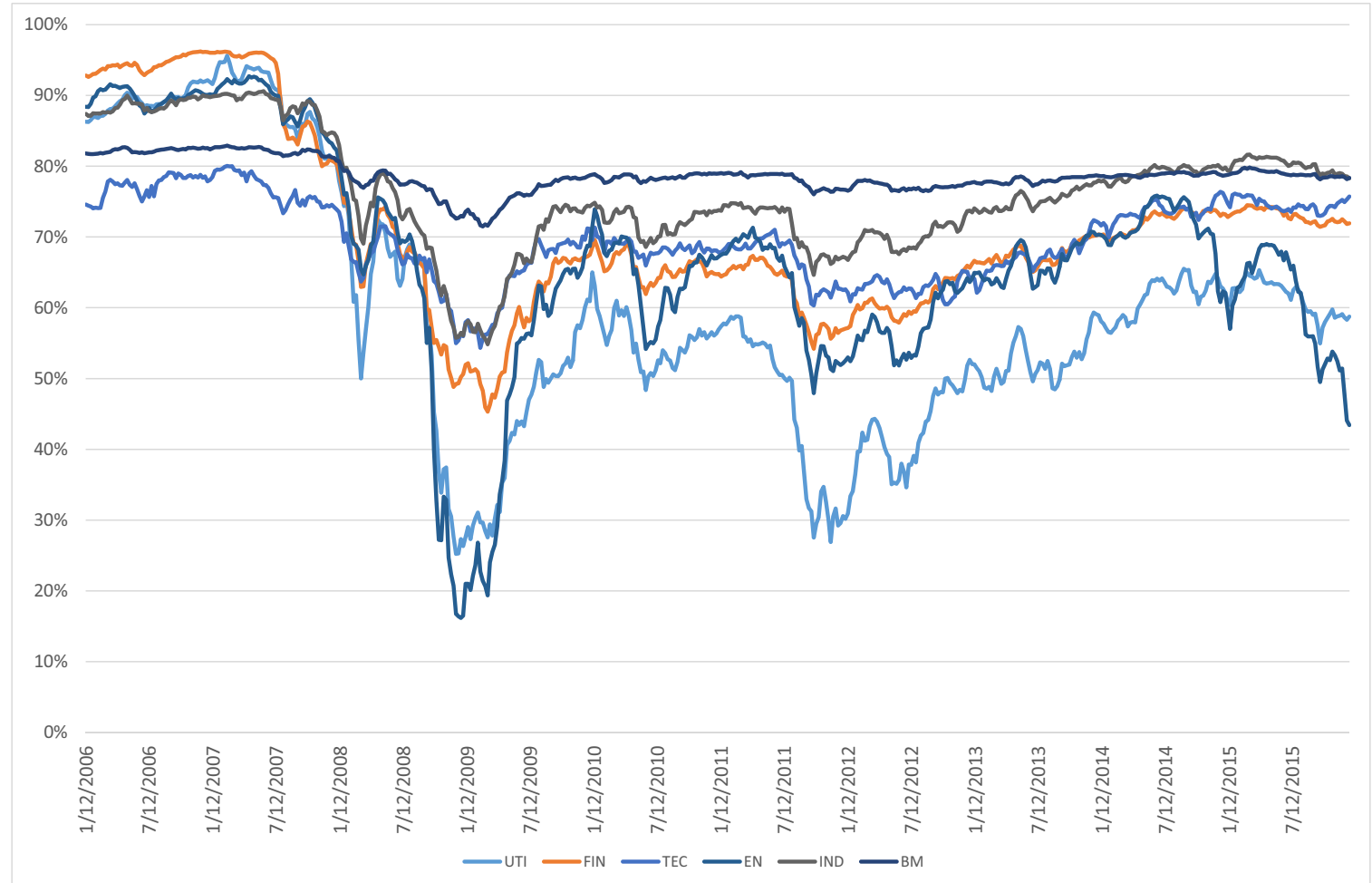

Note: The Figure shows the time evolution of estimates of the risk premium component of 10-year CDS spreads, as a percentage of the theoretical spread, for some selected sectors. 
Figure 5: Sectorial default-related spread indices

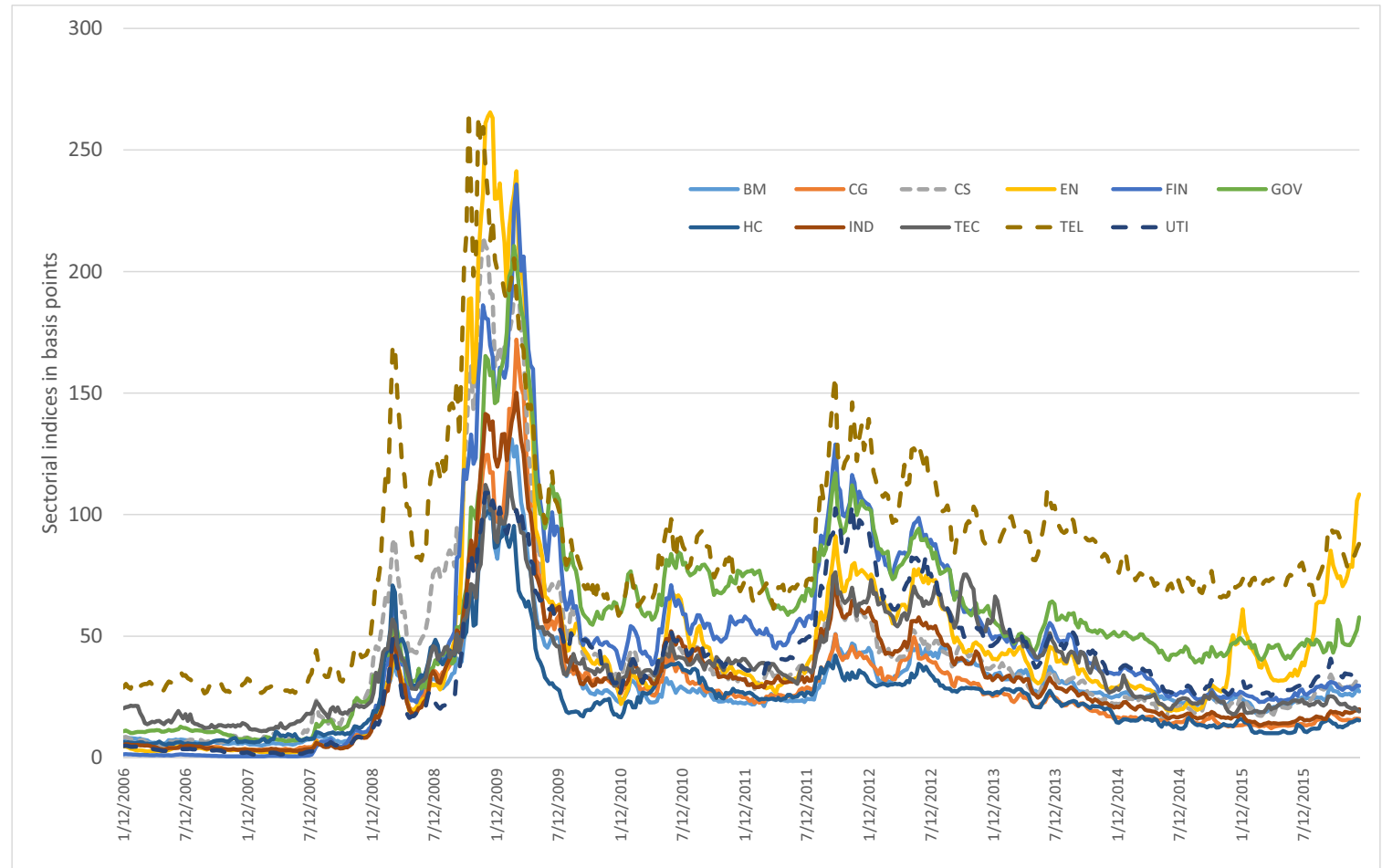

Note: The Figure shows sectorial CDS default-related spread indices. Each index was obtained as the first principal component of the defaultrelated component of spreads in that sector at the 5 tenors considered (1-, 3-, 5-, 7-, and 10-years).

Figure 6: Global credit risk factor

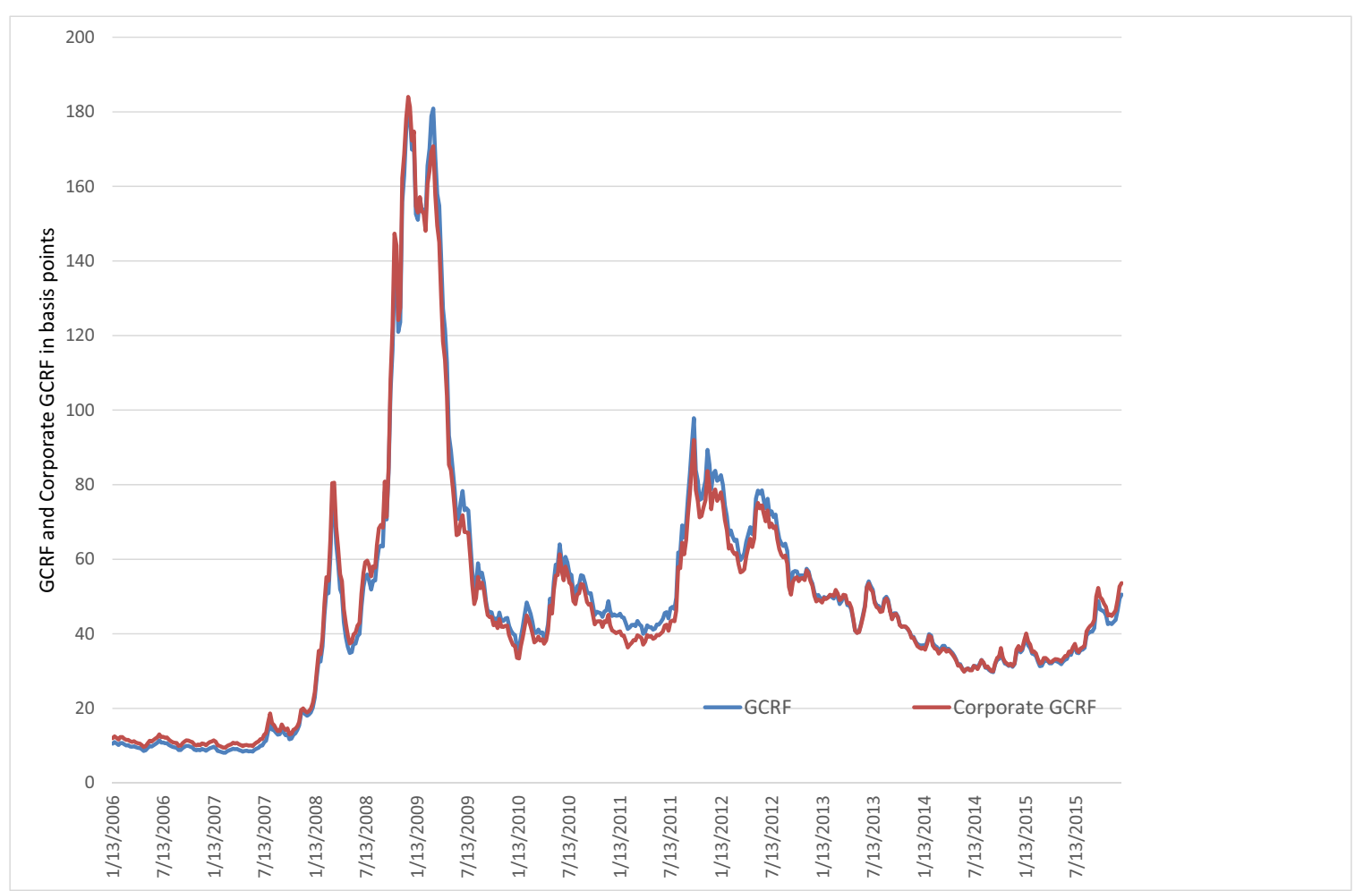

Note: The Figure shows estimates of the global credit risk factor (GCRF) and the Corporate GCRF. The latter excludes the Government and Financial sectors. 
Figure 7: Explanatory power of the global credit risk factor over time

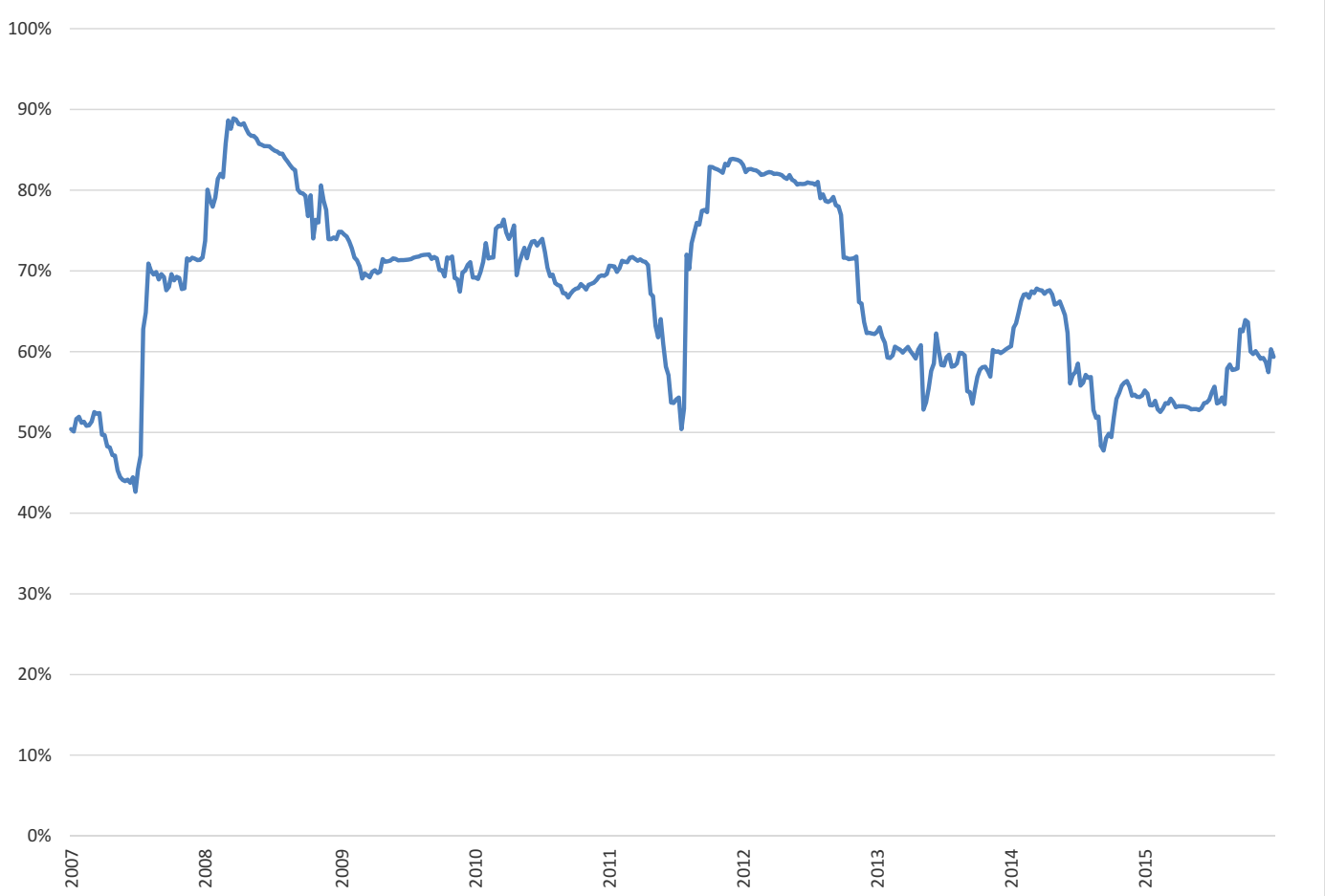

Note: The figure shows the percentage of variance explained by GCRF. The explanatory power of GCRF has been estimated using 52 -week rolling windows, as the ratio between the largest eigenvalue and the sum of all eigenvalues of the variace-covariance matrix of the set of time series for the 11 sectorial default indices.

Figure 8: Difference between the relevance of the systemic and idiosyncratic components of credit risk

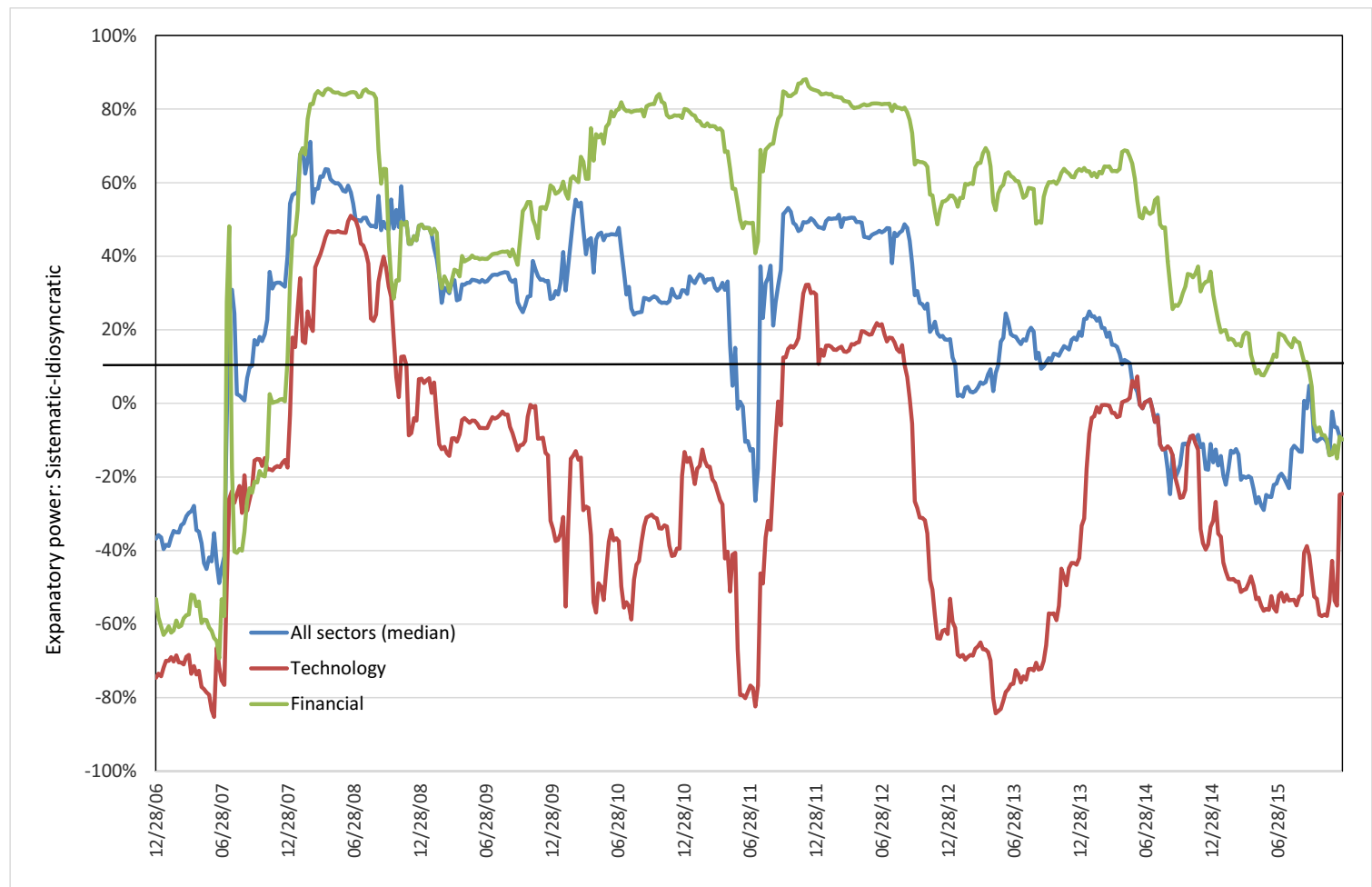

Note: The graph displays the median difference across sectors of the relevance of the systemic and idiosyncratic components of the defaultrelated component of CDS spreads. The relevance of the systemic component is measured by the Rsquared of a regression of each sectorial index on GCRF. The relevance of the idiosyncratic component is measured as 1 minus the previously mentioned Rsquared. The models were estimated using a 52-week rolling window sample. 
Figure 9: Scatter diagram between average annual GCRF and speculative grade default rate

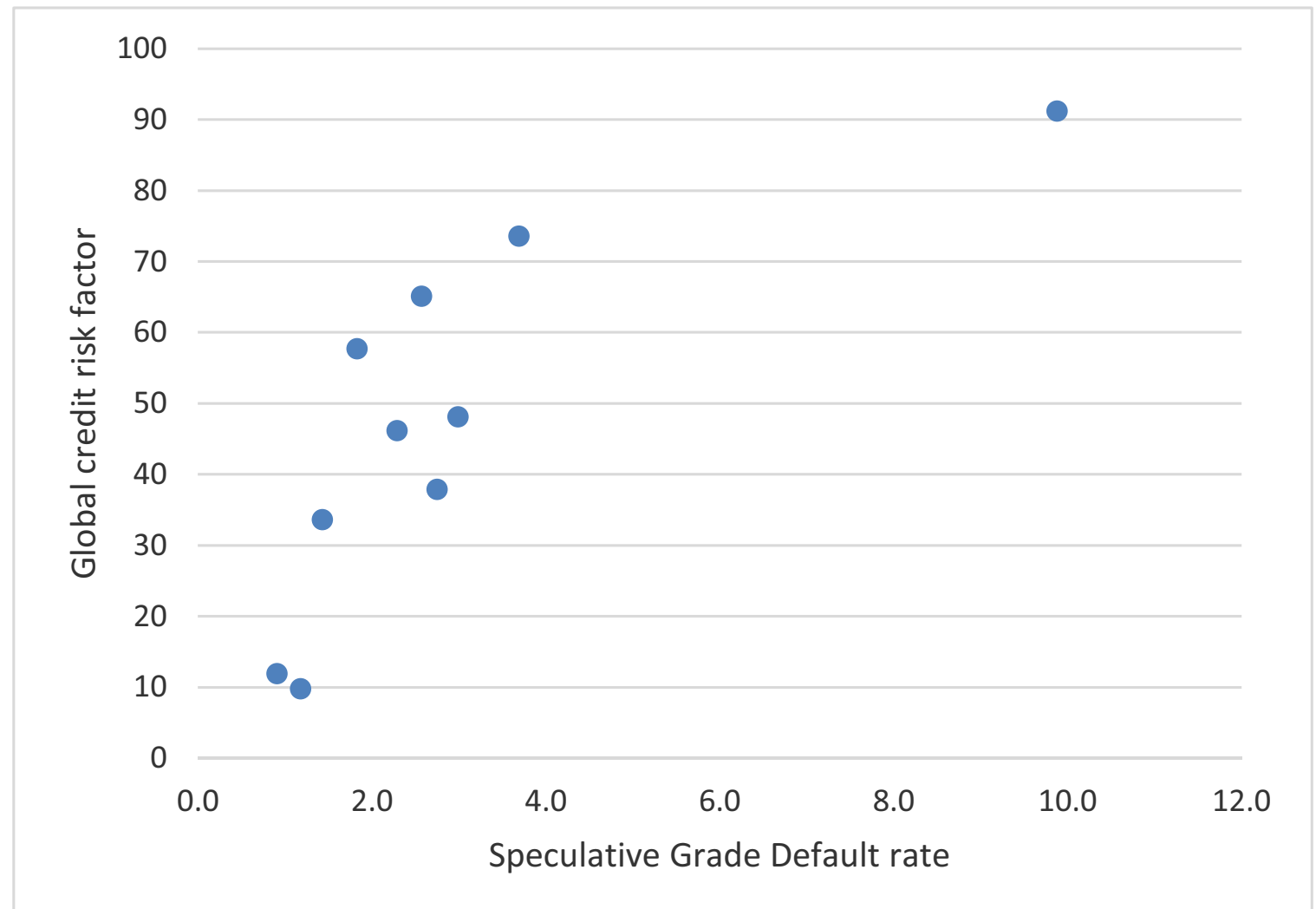

Note: The Figure compares the annual average GCRF versus the annual North American corporate speculative-grade default rate. Source: S\&P (2016)

Figure 10: GCRF and the Financial Stress Index of St. Louis Fed

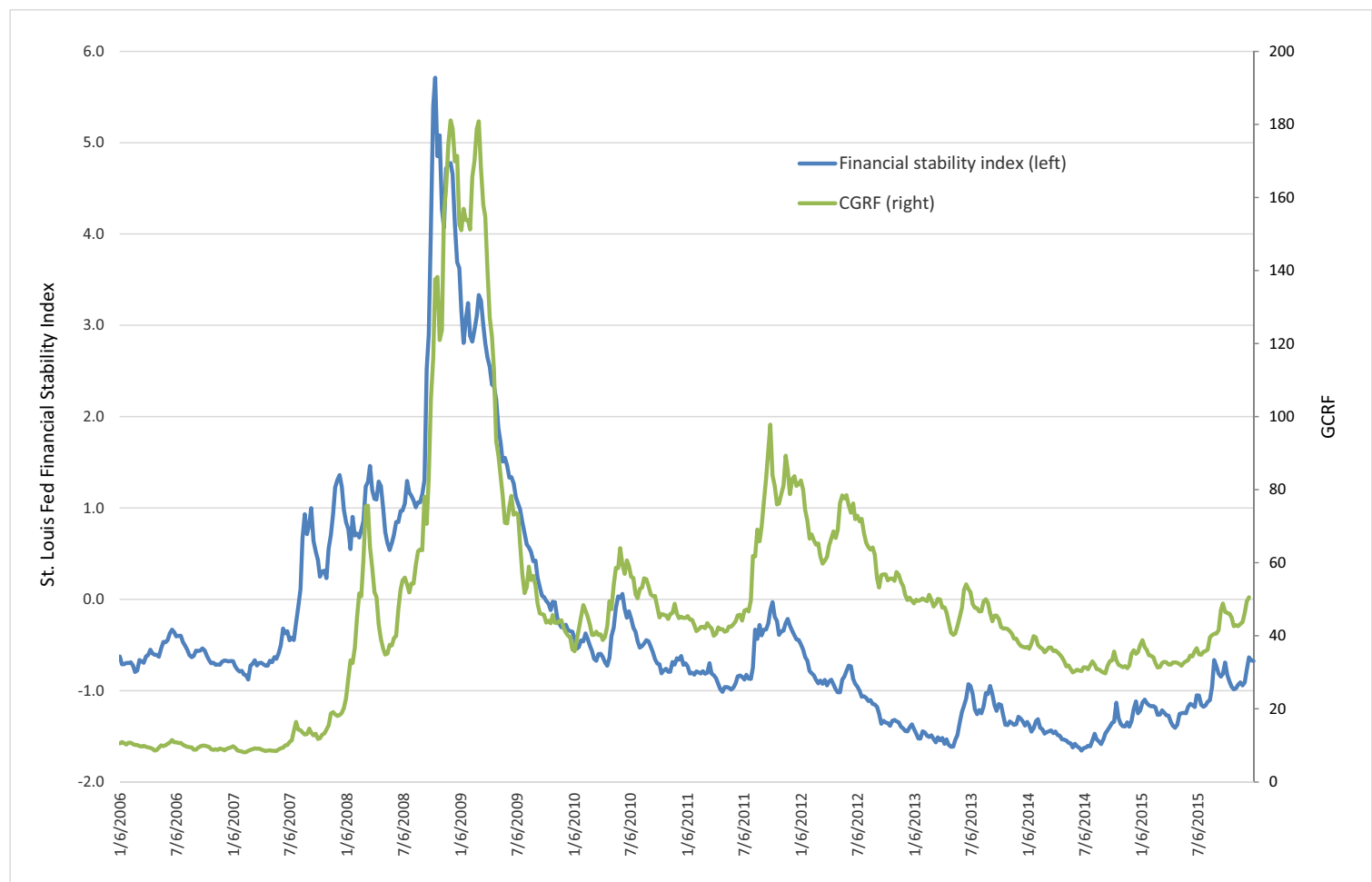

Note: The figure shows the time evolution of the estimated GCRF and the Financial Stress index of the Federal Reserve Bank of St. Louis. 
Figure 11: Time evolution of explanatory power of GCRF regressions

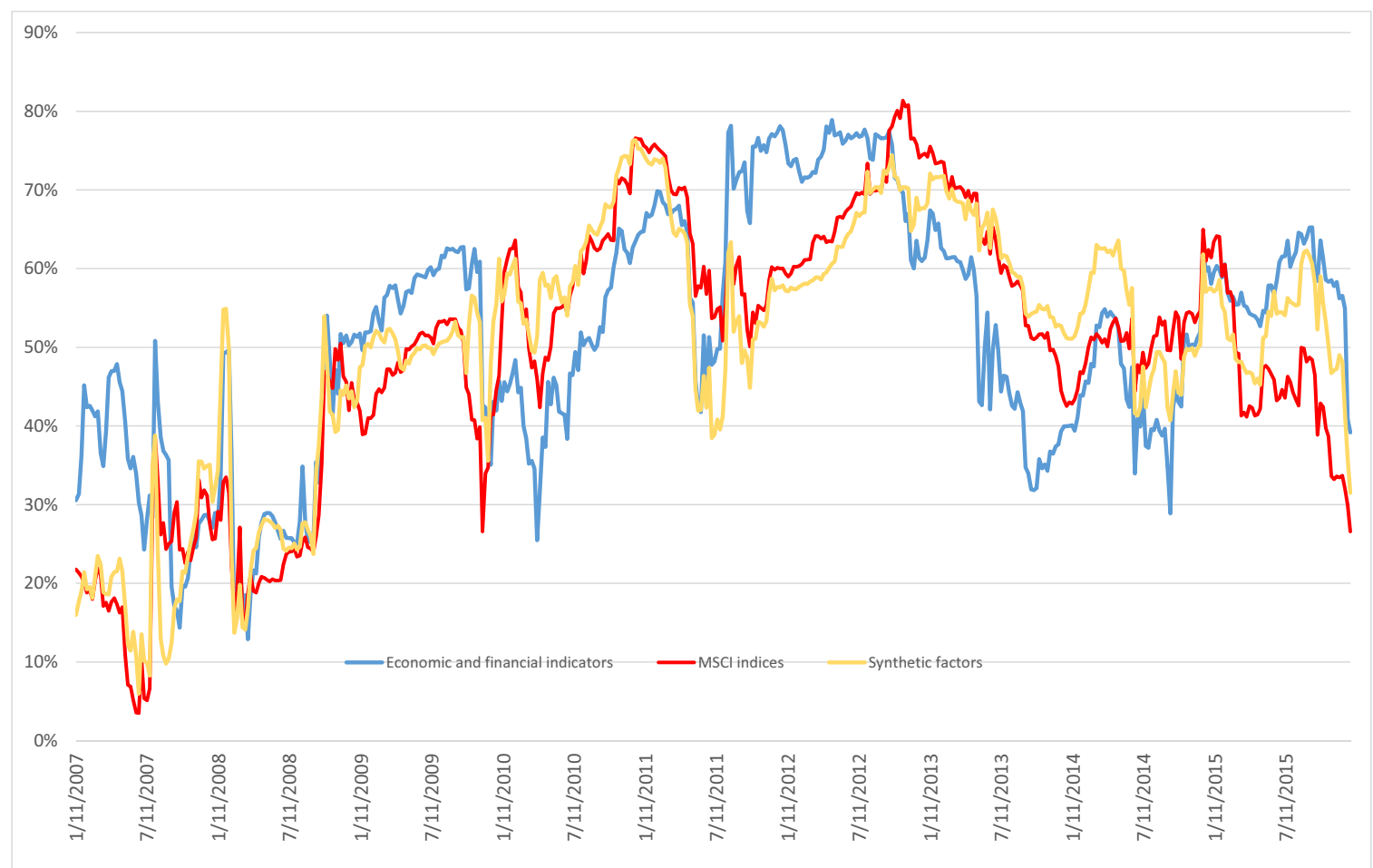

Note: The figure displays the explanatory power of first two regressions in Table 4, as well as that of the regression on the synthetic indicators (first regression in Table 5). Explanatory power is measured by the R-squared of 52-week rolling window regressions.

Figure 12: Estimated coefficients in synthetic factors regression

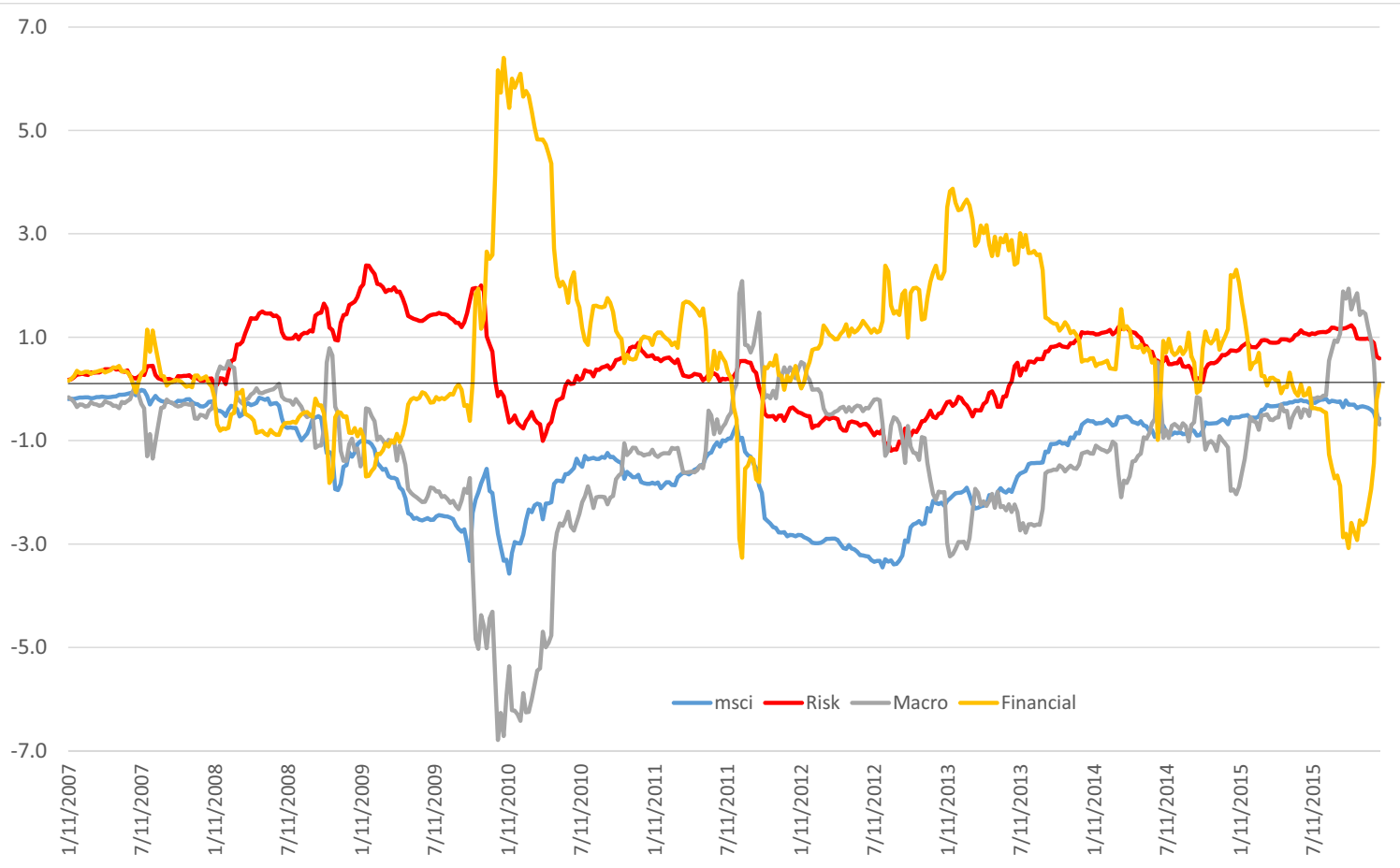

Note: The graph displays the time evolution of estimated coefficients for the synthetic factor regression. Estimates have been obtained from regressions using a 52-week rolling window sample. 
Figure 13: Quantile estimates of the synthetic factor regression, with 95\% confidence bands

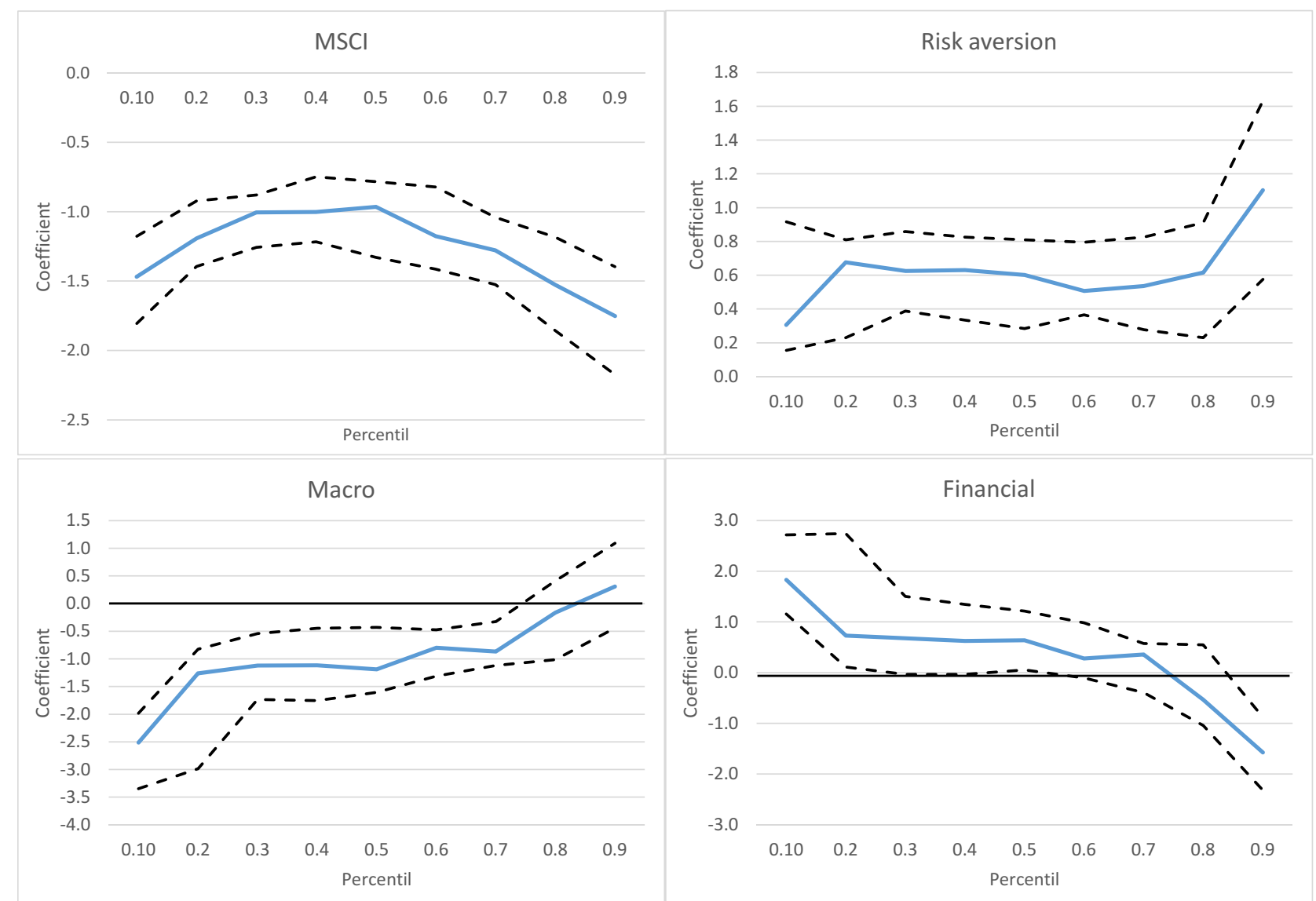

Note: The figure shows the values of each estimated coefficient in the synthetic factor regression for quantiles from $\mathrm{q}=0.05$ to $\mathrm{q}=0.95$. Dashed lines indicate 95 confidence bands. 
Figure 14: Observed and estimated CDS spread changes in stress periods

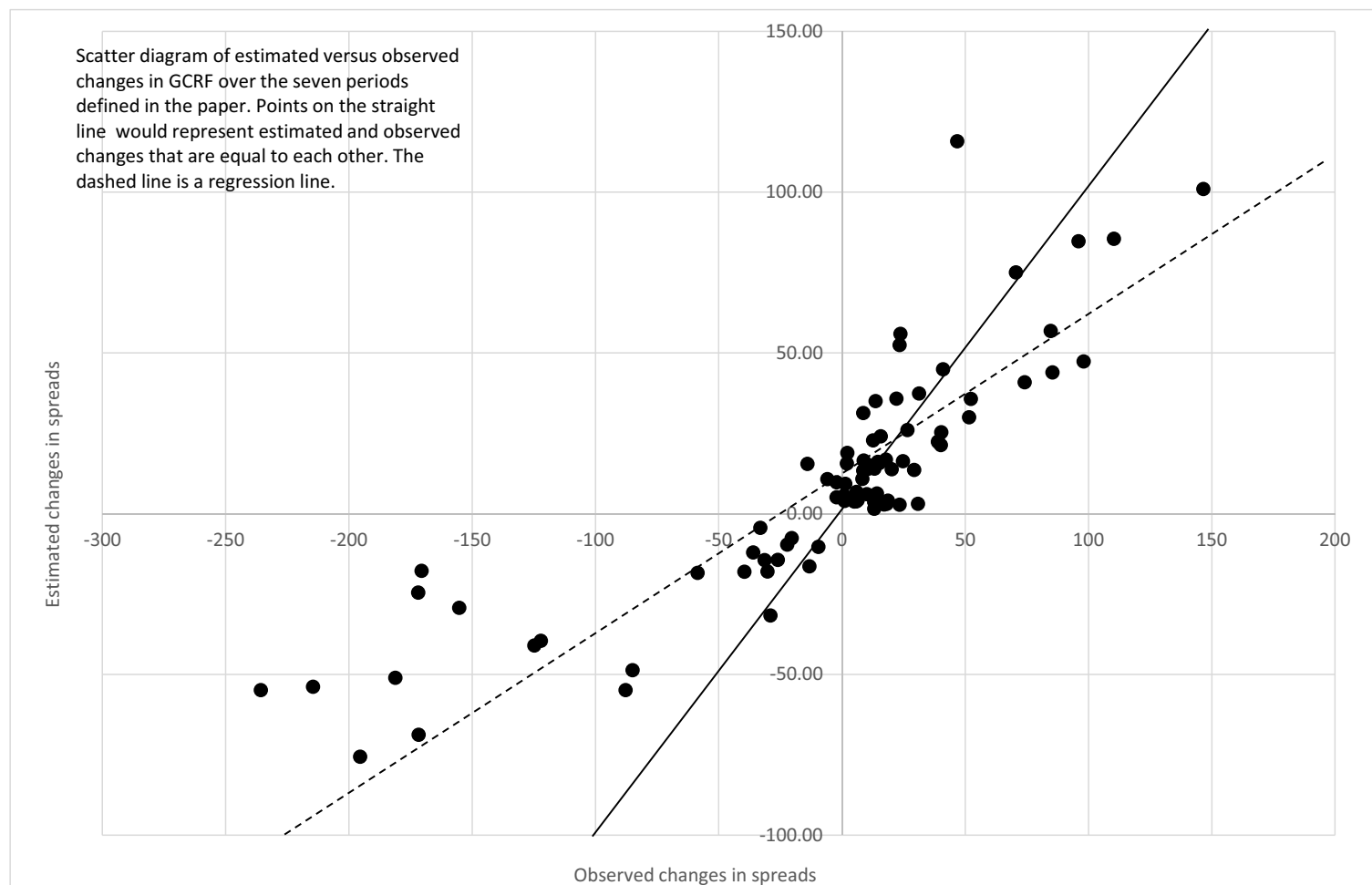

Note: The Figure shows a scatter diagram of estimated versus observed changes in CDS spreads across the 11 sectors, for the 7 stress periods considered in the paper.

Figure 15: Predicted spread increase from weekly stress test exercises

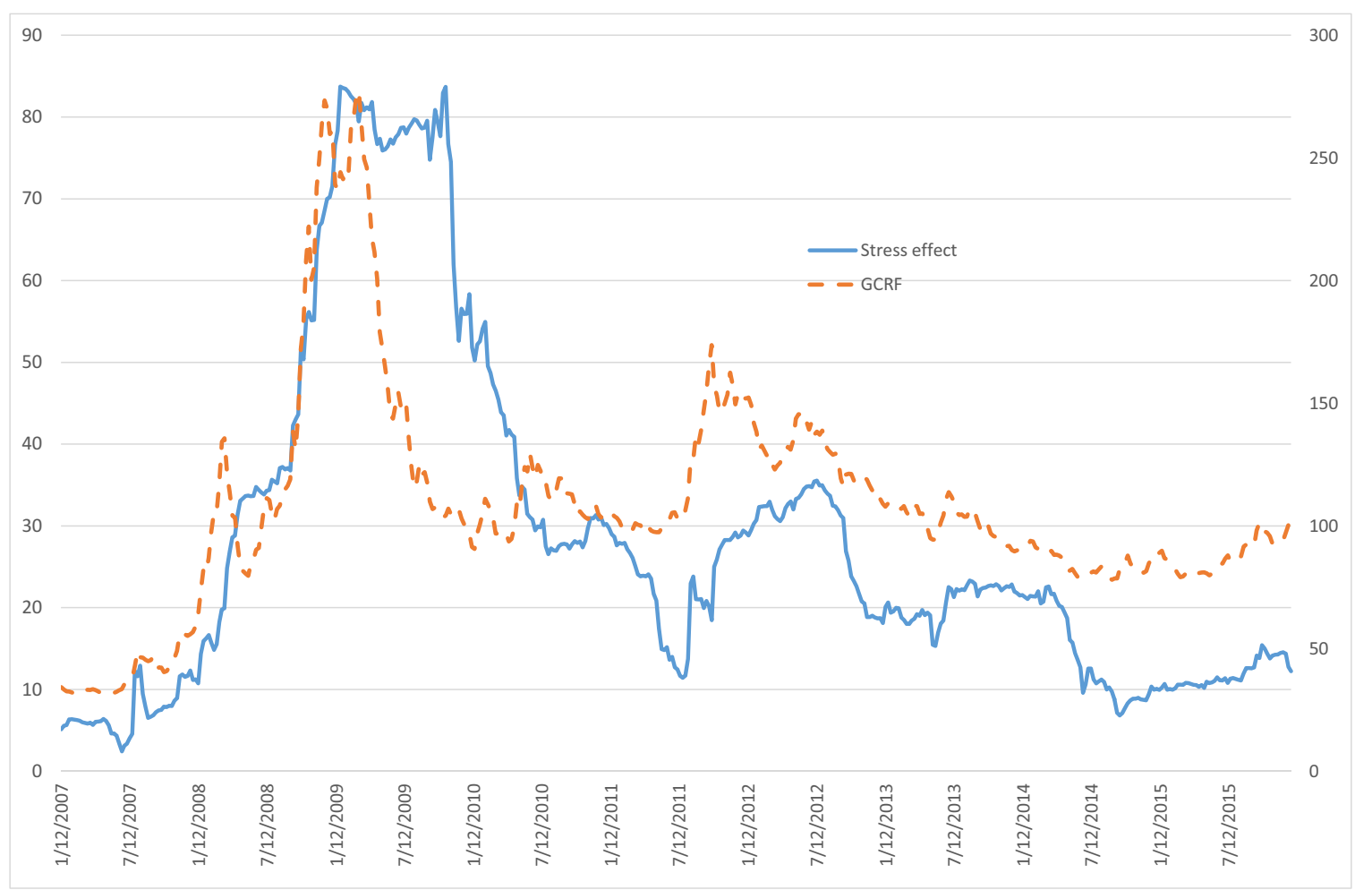

Note: The Figure shows the time evolution of the predicted change in CDS spreads from performing each week a stress test. The weekly stress test exercise uses a 52-week rolling window sample to estimate the synthetic factor model and assumes a change of 6 standard deviations in each factor in the direction of increasing CDS spreads. 
Figure 16: Observed and estimated weekly percent changes in portfolio CDS spreads

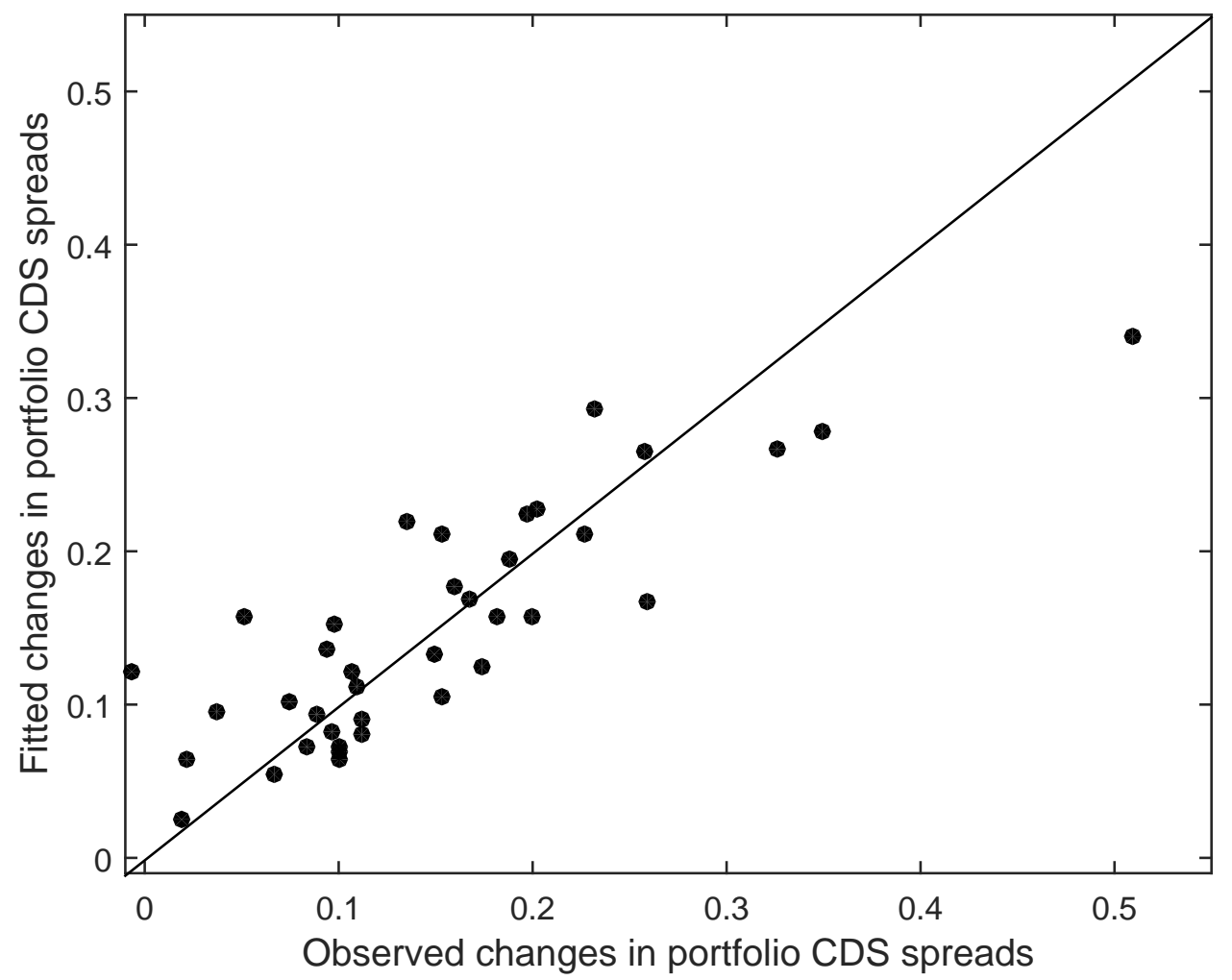

Note: The Figure displays the observed and fitted spread changes for 38 portfolios used in the Fama-MacBeth analysis, with the estimates from panel $b$ in 11 . The data shown are average weekly percent changes. Each portfolio is made up by 20 firms. Portfolios are rebalanced each week on the basis of the market index beta for the $760 \mathrm{CDS}$ contracts in the sample. A 52-week rolling window sample is used to estimate market-beta and GCRF-beta, as well as the market price of market-beta risk and GCRF-beta risk. The latter estimates provide us with the fitted portfolio spread changes. A perfect fit would place the points in the graph on the straight line. 